STAKEHOLDER PERCEPTIONS OF PROGRAMS AND SERVICES

PROVIDED TO GREEK CHAPTERS:

AN EXPLORATORY PROGRAM EVALUATION OF THE MISSOURI S\&T

FRATERNITY AND SORORITY LIFE OFFICE

\author{
A Dissertation \\ presented to \\ the Faculty of the Graduate School \\ at the University of Missouri-Columbia
}

In Partial Fulfillment

of the Requirements for the Degree

Doctor of Education

by

JAMES MURPHY

Dr. Jeni Hart, Dissertation Supervisor

December 2013 
The undersigned, appointed by the dean of the Graduate School, have examined the dissertation entitled

STAKEHOLDER PERCEPTIONS OF PROGRAMS AND SERVICES

PROVIDED TO GREEK CHAPTERS:

AN EXPLORATORY PROGRAM EVALUATION OF THE MISSOURI S\&T

FRATERNITY AND SORORITY LIFE OFFICE

Presented by James Murphy

A candidate for the degree of

Doctor of Education

And hereby certify that, in their opinion, it is worthy of acceptance.

Major Advisor - Associate Professor Jeni Hart

MU Division of Student Affairs Vice Chancellor Cathy Scroggs

Professor Emeritus Joe Donaldson

Associate Professor Bradley Curs

Assistant Professor Casandra Harper 


\section{Dedicated to}

my wife, Phyllis, who has always been at my side through this study, and the incredible student leaders of the Missouri S\&T Greek Community. 


\section{ACKNOWLEDGEMENTS}

I am deeply grateful to all the family members, friends, co-workers, and mentors who supported me while writing this dissertation.

I would like to thank the Educational Leadership and Policy Analysis faculty, especially my committee members Joe Donaldson, Cathy Scroggs, Brad Curs, and Casandra Harper, for their varied perspectives and the time and care they gave to this project. To my advisor, Jeni Hart, my gratitude cannot be expressed by words alone for her time and patience in helping me through what at times seemed like an unending task. Her feedback has helped me to become a stronger professional, a more adept writer, and a proponent of quantitative research. I will be forever indebted to her for her time, her attention, and her guidance throughout this process.

In addition to my committee there are others who have supported me through this process. My thanks go to my supervisor Debra Robinson for her unwavering support. My love and appreciation goes to Phyllis Murphy, my wife and life partner, for patently accommodating the time commitment this study made on both of us.

I have several friends, and colleagues who also deserve my thanks for their support and assistance. Included in this group are: Tina Sheppard; Edna Grover-Bisker; Angela Perkins, Katie Jackson, Brett Watson, Kristi Schulte, Marilyn Disser, F. Stephen Malott, Fr. Michael Murphy, Chris Ramsay, Sara Lindeman and my other friends, too numerous to list here, who have been a part of my life these past several years.

I have a wonderful family to also thank for their unconditional love and support. Erin, my oldest daughter and her husband Adam, Marn my bonus daughter and her husband Nick, my son Patrick, and my granddaughters; Caroline and Amelia.

My sincere thank you again goes out to each of you. 
ACKNOWLEDGEMENTS ................................................... ii

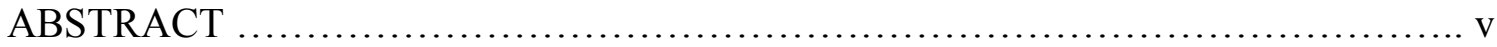

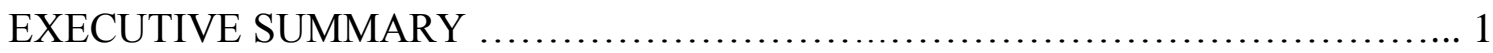

PROGRAM EVALUATION REPORT

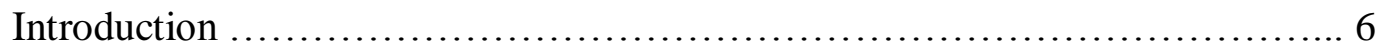

Significance of This Study ............................................ 11

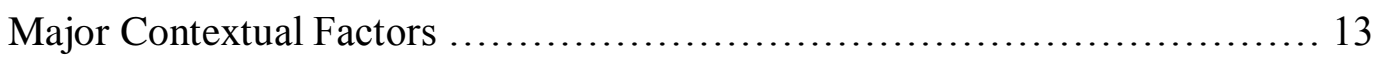

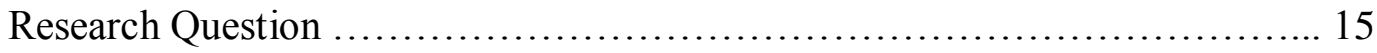

Overview of Methods ................................................. 15

Data Analysis .................................................... 16

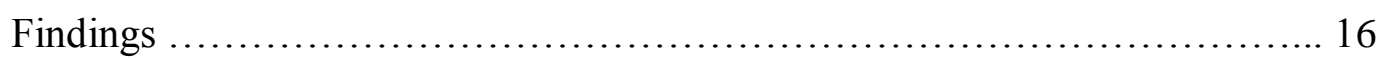

Implications, Limitations and Recommendations ........................ 29

Conclusion ....................................................... 34

APPENDIX

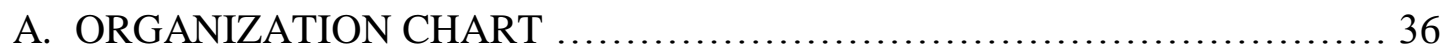

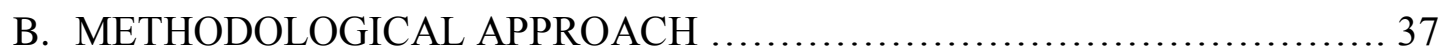

C. LITERATURE REVIEW ................................................ 57

D. CAS STANDARDS STAKEHOLDERS ASSESSMENT QUESTIONAIRE ...84

E. SUPERVISOR'S MEMO TO STUDENT LIFE OFFICE .................... 85

F. REQUEST TO PARTICIPATE IN A FOCUS GROUP DISCUSSION ......... 86

G. FOCUS GROUP GUIDELINES \& QUESTIONS ........................ 88

H. CAS STANDARDS SURVEY DETAILS ............................... 90

I. CAS STANDARDS 12 COMMON CRITERIA ............................. 100 
J. MISSOURI S\&T FRATERNITY \& SORORITY CHAPTERS ................. 104

K. IMPLICATIONS FOR FURTHER RESEARCH ….................................... 105

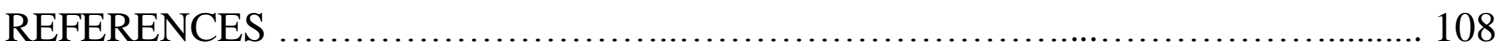

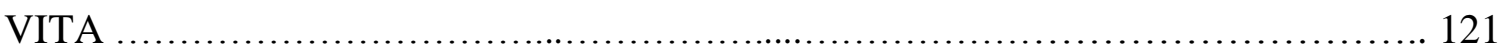




\title{
STAKEHOLDER PERCEPTIONS OF PROGRAMS AND SERVICES PROVIDED TO GREEK CHAPTERS: \\ AN EXPLORATORY PROGRAM EVALUATION OF THE MISSOURI S\&T FRATERNITY AND SORORITY LIFE OFFICE
}

\author{
James Murphy \\ Dr. Jeni Hart, Dissertation Supervisor
}

\begin{abstract}
The Missouri S\&T Fraternity and Sorority Life Office oversees a 24 chapter campus Greek community. This Office is responsible for providing this community with the necessary administrative support and program assistance needed for it to be a functional element of the University community. I conducted an exploratory case study that involved the Greek chapter officers and a sample group of Greek alumni to explore whether the Fraternity and Sorority Life Office complies with the CAS Standards for fraternity and sorority advising.

I collected data from Greek chapter leaders and affiliated Greek alumni by administering a CAS Standards survey and two focus group discussions. These data were aligned with five investigation categories in the CAS Standards survey questionnaire; the purpose of the Fraternity and Sorority Life Office; compliance with the CAS Standards; Program consistency with institutional mission; complementing the institutional mission; promotion of community development. This study's findings are intended to help this Fraternity and Sorority Life Office establish program goals that, once achieved, will improve this Office's client satisfaction with its services.
\end{abstract}




\section{Executive Summary}

This study was conducted to assist the Missouri University of Science and Technology (Missouri S\&T) Fraternity and Sorority Life Office set program goals and objectives. This Office has not held a goal program planning exercise since its inception in fall 1991.

The Fraternity and Sorority Life Office: The Missouri S\&T Fraternity and Sorority Life Office oversees 24 fraternity and sorority chapter organizations. Its services are supposed to support the growth and the development of the University's Greek community. The Fraternity and Sorority Life Office is a part of the University's Student Life Department. This department fosters campus community through student leadership development and student involvement. The Fraternity and Sorority Life Office shares this purpose thorough its efforts to address the program needs of the Greek chapters. The Fraternity and Sorority Life Office has a program coordinator, a quarter-time clerical staff member, and one or two part-time, paid student assistants.

Significance of This Study: Significant concerns have periodically been raised within the Missouri S\&T community regarding the Fraternity and Sorority Life Office's ability to oversee, and influence the campus Greek community (Norman, 2009). However, no data exist that either supports or refutes these perceptions. The purpose of collecting this type of data in this study was to provide this Office with information on its clients' perspectives regarding its programs and services using measures widely employed in the student affairs profession that can be used to develop program improvement goals.

Overview of Methods: This program evaluation was an exploratory case study that relied primarily on the CAS Standards Guidelines for Fraternity and Sorority Advisors to gather and analyze data. I employed a triangulated research strategy using multiple sources of data to improve reliability and credibility. Two methods were used to collect the data, a program standards survey and focus group discussions. The survey results were analyzed and presented using descriptive statistics. The focus group data was placed into thematic groups.

Findings: The survey and focus group findings were sorted and categorized to align with the five CAS Standard mission and program categories. Within these categories the survey data and focus group data were compared and contrasted. Some focus group findings were also placed in a sixth category that reflected pertinent comments made during the discussions that did not align with any of the five CAS categories. In this category, there was no attempt made to compare the discussion comments with any of the survey findings.

The focus group comments largely lent credence to the survey question findings. It was relatively simple to demonstrate student consensus with nearly all data collected in the focus group. The alumni participant perspectives concurred less often with the survey findings than did the student participant perspectives. The individual alumni participants' perspectives were also 
less uniform than those of the student focus group. If placed on a 5-point scale with a 5 being strongly agree and a 1 being strongly disagree, the alignment of the student focus group data with the corresponding survey questions generally fits closely in a 3.5 to 4.5 range while the alumni data would be less in agreement with the survey data and fell into a broader 2.5 to 4.5 range.

\section{Survey and Focus Group Findings}

Category 1: Understanding of the Purpose of the Fraternity and Sorority Life Office

The survey asked one question that related to this category and its corresponding mean score was 3.77. The following were the related focus group discussion themes:

- Participants' confusion or uncertainty regarding the purpose of this Office.

- All participants regard this Office's primary function to be the exercise some control over the Greek chapters.

- This Office was perceived as not being committed to advancing the chapters' welfare.

- This Office's priority was to advance the University's interests in the Greek community.

- The alumni participants viewed this Office as an impediment for their chapters.

\section{Category 2: The Fraternity and Sorority Life Office's Compliance with the CAS Standards}

The survey asked three questions that related to this category and their corresponding mean scores ranged from 4.0 to 4.24 . The following were the related focus group discussion themes:

- This Office's programs generally comply with the corresponding CAS Standards.

- The participants did not consider the CAS Standards as necessarily being relevant performance standards for this Office.

- Participants did not believe that complying with CAS Standards improved the quality of this Office's programs.

- Student participants generally confirmed the accuracy of the survey results but felt that these result were not significant.

- Student participants indicated that the respondents were not asked whether the CAS Standards were relevant, only if this Office complied with them.

\section{Category 3: The Extent to which Fraternity and Sorority Life Office Programs are Consistent} with the Missouri S\&T Mission and Values

The survey asked one question that related to this category and its corresponding mean score was 4.30. The following were the related focus group discussion themes:

- This Office's programs closely align with the University's interests.

- Being closely aligned with the University's interests diminishes this Office's value as a resource for the chapters.

- This Office could better serve the Greek community by serving more as a mediator between the Greeks and the University. 
Category 4: The Extent to which the Fraternity and Sorority Life Office Complements the Missouri S\&T Mission

The survey asked six questions that related to this category and their corresponding mean scores ranged from 4.0 to 4.21 . The following were the related focus group discussion themes:

- This Office sponsors program activities for Greek students and endorses the participation of Greek student in various campus programs.

- Participants questioned whether this Office places too much of a priority on aligning the University's mission with its clients' needs.

- Efforts by this Office to align itself with the University's mission is also seen as the Office endeavoring to complement the mission.

\section{Category 5: The Extent to which Fraternity and Sorority Life Office Promotes Community} Development

The survey asked one question that related to this category and its corresponding mean score was

4.11. The following were the related focus group discussion themes:

- Alumni, unlike student survey results, did not believe that the relationship between the University and the Greek community contained any mutually beneficial elements. The alumni description of this relationship was more akin to one where the University and its Greek Community "co-exist" with each other.

- The alumni saw Missouri S\&T and its Greek community functioning in parallel environments and the alumni are comfortable with this arrangement.

- The students were of the opinion that chapter involvement in campus seldom betters the University or their chapters.

- Chapter involvement in campus activities occurs when their participation may either aid a chapter in achieving recognition awards from national organizations or help a chapter's ability to recruit new members.

- Students spoke favorably of staff member efforts to engage with the officers and advise the Greek governing organizations.

\section{Category 6: Other Emergent Themes and Pertinent Focus Group Comments}

The following were relevant focus group discussion themes that were not directly related to any CAS themes:

- Students appreciated and respected the work being done by Brett Watson and Angela Perkins, the Fraternity and Sorority Life Office Coordinator and the Director of the Student Life Department, respectively.

- Students indicated that these staff members are good people who care about the students and are good to work with.

- While student leaders' perceptions of this Office remain relatively low, the working relationships between the Greek officers and this Office's staff are considered to be much stronger now than in past years. 


\section{Implications, Limitations, and Recommendations}

Participant interest in this Office being more of a Greek chapter advocate was a significant finding. It reflects a tension between the University's and this Office's client perspective regarding its desired purpose. This lack of a common understanding of this Office's purpose is related to nearly all other concerns voiced regarding this Office's programs and services. As a result of these findings, I propose the following implications and recommendations:

\section{The Purpose of the Fraternity and Sorority Life Office Must be Clearly Stated}

- There is no generally recognized statement delineating the purpose of this Office.

- Without a statement of purpose the student and alumni stakeholders will remain unaware of what programs or services can be expected to be provided.

\section{The Mission of the Fraternity and Sorority Life Office}

- The Fraternity and Sorority Life Office Web site banner reads; "Missouri S\&T Fraternity \& Sorority Life is committed to creating a positive, values-based fraternal experience by providing first class leadership, educational, service, and social opportunities that complement the University's educational mission." None of the participants in this study were aware of this mission statement.

- A recognized mission is necessary. Such a statement is the essential first step needed to begin to educate these clients regarding the reason for the existence of this Office.

\section{The Significance of the Fraternity and Sorority Life Office}

- Clients perceive this Office to not be a significant contributor to the Greek community.

- Greek leaders consider this Office's primary function to be the mechanism for assuring Greek chapter compliance with University policies.

- This Office's role in improving the Greek community must be delineated and made known.

\section{Alignment of the Fraternity and Sorority Life Office Goals and Objectives}

- This Office needs goals that consider the interests of its clients, the University's expectations and the expectations of Greek national associations.

- An inquiry into client needs is warranted to better guide the efforts of this Office.

- A goal setting exercise involving this Office and its clients might assure that a connection forms between the chapters, the University, and national fraternal organizations.

\section{Future Use of CAS Standards as a Fraternity and Sorority Life Performance Standards}

- Inconsistencies between survey results and focus group findings suggest that most participants either were not familiar with or did not find these standards to be important.

- This study's survey and information materials should have been more thoroughly pre-tested to be better suited to the student population at Missouri S\&T.

\section{Conclusions}

1. The Fraternity and Sorority Life Office is an Unknown Commodity for Much of the Greek Community. Participant ambiguity over this Office's purpose is an overarching issue in this study's findings. 
2. This Study Revealed Some Previously Unrecognized but Useful Goal-Setting Information . This program evaluation provides some valuable stakeholder insights which had not previously been discovered that will be included in this Office's planning of future goals.

3. A More Comprehensive Inquiry into Customer Preferences Will Eventually be Necessary. To be effective measures, future evaluations of programs need sample groups that are more diverse and more representative of the actual Greek student and alumni populations than the sample group used in this study.

4. Good Preparation of the Study Participants is Desirable. To the extent that circumstances will permit, future studies should incorporate means that ensure that participants understand the study's purpose.

5. The CAS Standards. Further consideration is needed regarding how the CAS Standards are used prior to attempting a similar application within the Missouri S\&T campus community. This study's findings suggest that prior to their future use with the Missouri S\&T students, a better strategy is needed for preparing students to apply them within the desired context of a study. 


\section{PROGRAM EVALUATION REPORT}

\section{Introduction}

This study was conducted to assist the Missouri University of Science and Technology (Missouri S\&T) Fraternity and Sorority Life Office, along with its parent department, the Student Life Department to set their goals and plan their efforts for working with the campus Greek community.

The Missouri S\&T Fraternity and Sorority Life Office oversees the chapter organizations that comprise the campus Greek community. The intent of its programs and its services is to support the growth and the development of the Greek community primarily through leader development and other administrative services. Since its creation in 1991, the Fraternity and Sorority Life Office has been a part of the University's Student Life Department. In performing its primary function, the Fraternity and Sorority Life Office oversees the activities of the 24 Missouri S\&T recognized fraternity and sorority chapters.

The Student Life Department is expected to aid in fostering a healthy campus community environment, encourage student leadership development, and promote student involvement. To support these endeavors, this Office has access to a program account to fund leadership and officer training opportunities. This fund is also used to procure office supplies, printing, recognitions, and programming materials.

The Student Life Department's program and service activities reflect the University's expectations for this department and can be grouped into three operational themes: overseeing and advising University recognized student organizations; approving and providing administrative support for University sanctioned student activities; and designing and implementing various personal development opportunities (Missouri S\&T, 
Office of the Chancellor, 2010). As a part of this department, the Fraternity and Sorority Life Office shares this purpose with a concentration on addressing the program needs of a particular campus student population, the Greek chapters.

\section{Affiliation with the Student Life Office.}

The Missouri S\&T Student Life Department's programs and services are available to all University students and all of its recognized student organizations. The Fraternity and Sorority Life Office is responsible for overseeing the programs and support services provided specifically the Missouri S\&T's fraternity and sorority chapters (Missouri S\&T, Student Life Office, 2011). To receive assistance from the Fraternity and Sorority Life Office, a fraternity or a sorority chapter must be a University recognized student organization. Obtaining University recognition requires an organization to complete an approval process. Once approved, an organization is eligible for various forms of University support, including but not limited to: access to student activity fee funds; use of the University's facilities; and administrative, advising and bookkeeping assistance (Missouri S\&T, Student Life Office, 2011).

The assistance most often requested from the Fraternity and Sorority Life Office is aid in accessing one or more of the University's various administrative processes from the Fraternity and Sorority Life Office. Examples include: accessing the University's database to generate member information reports, purchasing goods or services through the University's procurement process, and reserving the use of the University's facilities. The Fraternity and Sorority Life Office also provides the Greek community with other program and service support. Most often this support is provided to improve the caliber of a Greek organization's operations or to help enhance the skill levels of members, chapter leaders, and advisors. The Greek chapters and governing council leaders also 
regularly access clerical support from this unit. This Office also serves the Greek community by overseeing its major social activities, and by monitoring chapter compliance with applicable campus policies (Missouri S\&T, Office of Fraternity and Sorority Life, 2011).

\section{Fraternity and Sorority Life Office staff and University Affiliated Entities}

Because the Fraternity and Sorority Life Office is a subset of a larger department, it is challenging to precisely identify its staff members. While only one fulltime Student Life Department staff member is formally assigned to this Office, there are other department staff members who play roles in providing programs and services. For the purpose of this study, any department staff member who is regularly involved in the functions of the Fraternity and Sorority Life Office are considered a part of its staff. Those who spend on average, a minimum equivalent of one day per week performing work directly associated with the Fraternity and Sorority Life Office will be considered regular staff.

\section{Department Staff}

The Fraternity and Sorority Life Office has an assigned staff that includes a program coordinator, a quarter-time clerical staff member, and one to two part-time, paid student assistants. These individuals are involved daily with the Fraternity and Sorority Life Office. In addition, the Student Life Director is routinely involved with this Office and is considered one of its staff members. Because the Fraternity and Sorority Life Office is within the Student Life Department, this director supervises this Office. The supervisory responsibilities of the Student Life Director include: overseeing all personnel decisions; evaluating staff member performance; and overseeing all purchases. The Student Life Director regularly represents the Fraternity and Sorority Life Office at 
campus functions. This person is also an active participant in designing and implementing most of the office's major events.

The Fraternity and Sorority Life Office and the other Student Life Department staff are closely associated with each other. They share an office suite and clerical support, and have a common supervisor. All the Student Life Department personnel routinely contribute their time and expertise to help to implement many of the Fraternity and Sorority Life Office's activities and services. Because of the degree and frequency of these staff members' formal and informal interactions, all the Student Life Department staff is considered contributing members of the Fraternity and Sorority Life Office (Appendix A).

\section{Affiliated University Entities}

The Fraternity and Sorority Life Office also receives considerable collective support from some of the other University's Student Affairs Division offices. The Fraternity and Sorority Life Office involvement with these entities is sufficient for them to be considered potential stakeholders. However, none of these external entities receive a notable amount of program support from the Fraternity and Sorority Life Office. They also do not individually provide sufficient support at a level of frequency to be considered an integral part of the staff of this Office.

Of these other entities, the University's Residential Life Department is most frequently involved with the Fraternity and Sorority Life Office because each of the 22 Greek chapter houses is a University approved student residence. The Residential Life Department is responsible for overseeing their adherence to the University's residency policies and compliance with the University's standards for approved student housing facilities (Missouri S\&T, Department of Residential Life, 2011). This department is also 
the repository for all the University's approved student housing information including: housing rosters, resident student information, Greek chapter membership rosters, and chapter house facility information. As such the Residential Life Department is the Fraternity and Sorority Life Office's best source for most of the University's Greek chapter demographic and academic performance data (Missouri S\&T, Department of Residential Life, 2011).

The Fraternity and Sorority Life Office also receives a notable amount of assistance from a few other University offices and departments. The Student Affairs Community Standards Office works with the Fraternity and Sorority Life office on matters regarding compliance with the University's individual and organization conduct policies (Missouri S\&T, Office of the Vice Chancellor for Student Affairs, 2011). The University's Counseling Center, Wellness Programs Office, and Cultural Programs Office each provides resource or expertise support for Fraternity and Sorority Life Office program activities (Missouri S\&T, Office of the Vice Chancellor for Student Affairs, 2011).

\section{Missouri S\&T Greek Community}

The collective student membership in Missouri S\&T Greek chapters is slightly more than $20 \%$ of the University's undergraduate student population and their numbers constitute $12 \%$ of the University's 205 approved student organizations (Missouri S\&T, Student Life Office, 2011). While similar to other student groups in that they must comply with the same University policies and recognition standards as other organizations, the Greek chapters differ due to the frequency of member activities. The fundamental nature of Greek letter organizations encourages social bonds to develop among members. Forming these bonds often results in daily, formal and informal 
interaction among members (Jelke \& Kuh, 2003). This regular member interaction among Greek students tends to be more intense than is the interaction among members of other student organizations (Jelke \& Kuh, 2003; Norman, 2009). These Greek member interactions are particularly evident among members residing in Chapter houses.

At Missouri S\&T, 22 of its 24 chapters operate houses and over $80 \%$ of the active Greek members are residents (Missouri S\&T, Fraternity and Sorority Life Office, 2011). This is in contrast with most other student organizations where members engage each other periodically, primarily during their scheduled meetings and other planned events. With a Greek population that is proportionally larger than on most campuses (Brown, 2007; Jelke \& Kuh, 2003) and with most active members residing together, the Missouri S\&T fraternities and sororities constitute the Student Life Department's largest individual subset of student groups. The resources allocated to the Fraternity and Sorority Life Office reflect this point. Almost $40 \%$ of the Student Life Department's staff time and programming funds are dedicated to this Office.

\section{Significance of This Study}

Periodically, during the past several years, individuals and groups within the University community have raised concerns regarding the Fraternity and Sorority Life Office's ability to support, oversee, and effectively influence the campus Greek community (Norman, 2009). However, at this time, no data exist that can support or refute these perceptions. The lack of any data makes a program evaluation to establish a performance benchmark. Without such a standard, it is impossible to measure progress made toward achieving future goals.

Further, the Fraternity and Sorority Life Office does not have in place any formal goals or a strategic plan. This limits the Student Life Department's ability to identify 
accountability measures for the staff of the Fraternity and Sorority Life Office. The absence of organizational goals also hinders this Office's ability to develop effective strategic or tactical plans that recognize and help to address needed program improvement needs (Koepsell, 2008).

There are also concerns within the University community regarding the caliber of the chapters' leadership (Norman, 2009). The officers, active alumni, and advisors have primary responsibility for organizing and executing chapter activities and services. However, lacking a goal setting strategy, the Fraternity and Sorority Life Office, and in turn the chapter leaders, have relied on achieving tasks as they emerge as the means for determining their objectives. This method for determining objectives results in decisions being made in ways that impact immediate issues but lack the foresight needed to intentionally influence the longer term and the overall well-being of their Greek chapter members or to improve their organization (Asel, Seifert \& Pascarella, 2009; Burns, 1978).

As a result of the needs for benchmarking, goal setting, and planning I conducted an evaluation of the Missouri S\&T Fraternity and Sorority Life Office focused on its stakeholders' perceptions of its programs and services. The information collected will now serve as a basis for developing this Office's organizational goals and objectives. This program evaluation has the following potential benefits for the Fraternity and Sorority Life Office, the Student Life Department, and the Missouri S\&T Student Affairs Division:

- Program evaluations have rarely been conducted among Missouri S\&T student organizations and have been only occasionally conducted within the Student Affairs Division offices or departments. This evaluation of the 
Fraternity and Sorority Life Office serves as a model for subsequent applications within the Student Affairs division.

- The Fraternity and Sorority Life Office has no formal means for obtaining any input from its stakeholders regarding the Office's programs and services. This evaluation provides a method for gathering stakeholder information.

- This program evaluation is an impetus for a Fraternity and Sorority Life Office goal setting exercise. This is an opportunity to establish a set of data driven, achievable goals that can improve the effectiveness of this Office's programs and services and in meeting constituent needs.

- While this study's findings will have not any bearing on the evaluation of staff members' performance, it is possible that they may contribute to the development of a future tool for evaluating performance.

\section{Major Contextual Factors}

There are some contextual factors that merited consideration during this program evaluation. I anticipated these factors to be the most significant:

- This study is framed as a program evaluation guided by a set of external standards that were developed and advocated by the student affairs profession (Miller, 2003; Upcraft \& Schuh, 1996). They were chosen to help assure credibility in the study's findings.

- This study follows an accepted logical sequence by addressing the first seven of the ten steps defined in a commonly applied student affairs benchmarking model, the Council for the Advancement of Standards (CAS) (Upcraft \& Schuh, 1996). This study stopped at step seven because it is a first step in a longer continuous improvement process. Steps eight, nine, and ten represent 
the steps that should be implemented after this study is completed. These benchmarking steps are:

1. Define problems and issues

2. Establish the need for benchmarking or for external standards

3. Decide what to measure

4. Identify involvement in the study

5. Define organizations to use for determining benchmarks or standards

6. Establish what data is desired

7. Analyze data

8. Adapt data and use to facilitate program improvements

9. Monitor results

10. Assess outcomes

- The involved stakeholders hold varying perspectives regarding their roles. This is largely due to their degree of involvement as well as the extent of the influence exercised by external factors (e.g., alumni, national offices, landlords, etc.), which vary considerably among chapters. For the purpose of this study, I was primarily interested in the perceptions of Greek student leaders and secondarily of alumni.

\section{Research Question}

This program evaluation was an exploratory, improvement oriented, formative study. My interest in conducting this study lies in its potential to gather client perceptions of the Fraternity and Sorority Life Office. My purpose for gathering this information was to provide this Office with information about its clients' perspectives regarding its 
programs and services that can be used to develop program improvement goals. This study gathered its information by investigating this question: To what extent do the clients of the Missouri S\&T Fraternity \& Sorority Life Office feel that this Office complies with the CAS Standards for Fraternity and Sorority Advising?

Overview of Methods

This exploratory case study (Yin, 1994) focuses on the Fraternity and Sorority Life Office's outputs. Because no existing systematic process is in place for conducting a program review for this Office, I relied primarily on the CAS Standards Guidelines for Fraternity and Sorority as my model to direct this study's data collection, analysis, and evaluation (See Appendix B for details about this study's methods).

This case study applied a triangulated research strategy that used multiple sources of data to improve reliability and credibility (Yin, 1994). Triangulation in a case study is accomplished by using different forms of data, multiple investigators, multiple theories, or different methodologies. In this case study, this was done by using multiple data collection methods.

I used two primary methods to collect the data. These inquiry instruments included a program standards survey (Appendix D) and focus group discussions (Appendix G). The survey questions were adapted from the mission and program elements of the CAS Standards assessment guide for Fraternity and Sorority Advising and were administered to the Greek chapter executive officers. The two focus group discussions were held after the survey was completed and involved chapter Presidents and Greek alumni. The discussion questions used in the focus groups were also derived from this same CAS Standards assessment guide. (See Appendix B for details about this study's data collection methods) 
In spring 2013, I administered a survey to 148 active Greek chapter officers. Forty seven participants returned completed surveys. Once survey data was analyzed, I conducted the two focus group sessions. One group session was comprised of eight Greek officers who were among those completing the survey. The other group was a smaller, four member sample group of Greek chapter alumni.

\section{Data Analysis}

The survey results were analyzed and presented using descriptive statistics. The survey information was calculated to show the means for each survey item for the entire set of respondents. The mean was also calculated for the following groups; chapter presidents; all other participating student leaders; male student leaders; and female student leaders. I also conducted T-tests to determine if there is a significant difference between these leader subgroups. No attempt was made to generalize this information to order to make any inferences regarding a larger population (Appendix $\mathrm{H}$ ).

For the focus group data, I read each transcript and identified the frequencies of particular ideas and the sources of these ideas. I then analyzed these data for common themes. I next identified the comments that were related to these themes and placed the comments into these thematic groups (Carey \& Smith, 1994). These common groups were then aligned into one or more clusters that aligned with the five identified CAS Standards question categories. As a validity check, I also had a colleague who had assisted in facilitating these focus group discussions review the consistency of my data groupings.

\section{Findings}

The survey and focus group findings were sorted and categorized to align with the five CAS Standard mission and program categories. Within these categories the survey 
data and focus group data were compared and contrasted with the survey results. Some focus group findings were also placed in a sixth category that reflected pertinent comments made during the discussions that did not align with any of the five CAS categories. In this category, there was no attempt made to compare the discussion comments with any of the survey findings.

\section{Survey Summary}

There were 148 surveys distributed to Greek chapter leaders. From that distribution, 47 (32\%) were returned. Broken down by officer group; 24 surveys were sent to and $12(50 \%)$ were returned by chapter presidents; 124 were sent to and 35 (28\%) were returned by other chapter officers. Broken down by sex; 121 were sent to and 36 $(30 \%)$ were returned by male officers; and 27 were sent to and $11(41 \%)$ were returned by female officers.

A 5-point response scale was used in all the survey questions. The response scale choices were:

$$
\begin{aligned}
& \text { 1- Very Poor; No effort to meet criteria; } \quad 2 \text { 2- Poor; Criteria not met; } \\
& \text { 3- Fair; Criteria minimally met; } \quad \text { 4- Good; Criteria well met } \\
& \text { 5- Very Good- Criteria fully met }
\end{aligned}
$$

The survey responses by population group and their mean averages are presented ion the following table: 


\begin{tabular}{|c|c|c|c|c|c|}
\hline CAS Standards Survey Question & Presidents & $\begin{array}{l}\text { All Other } \\
\text { Officers }\end{array}$ & Male & Female & All \\
\hline $\begin{array}{l}\text { 1. The purpose of the Missouri S\&T Fraternity and Sorority Life } \\
\text { Office is unders tood by the Greek community members }\end{array}$ & 3.92 & 3.71 & 3.75 & 3.82 & 3.77 \\
\hline \multicolumn{6}{|l|}{$\begin{array}{l}\text { 2. To comply with the CAS Standards described above, to what } \\
\text { extent does the Fraternity and Sorority Life Office: }\end{array}$} \\
\hline $\begin{array}{l}\text { a. Conduct its activities in ways that are consistent with these } \\
\text { standards }\end{array}$ & 4.25 & 4.20 & 4.22 & 4.18 & 4.21 \\
\hline $\begin{array}{l}\text { b. Incorporate learning and student development outcomes into its } \\
\text { programs }\end{array}$ & 3.75 & 4.09 & 3.94 & 4.18 & 4.00 \\
\hline $\begin{array}{l}\text { c. Promote academic and personal growth and development of } \\
\text { affiliated students }\end{array}$ & 4.08 & 4.29 & 4.17 & 4.45 & 4.24 \\
\hline $\begin{array}{l}\text { 3. To what extent does the Fraternity and Sorority Life Office } \\
\text { implement programs \& services that are consistent with } \\
\text { Missouri S\&T's mission and values }\end{array}$ & 4.50 & 4.23 & 4.33 & 4.18 & 4.30 \\
\hline \multicolumn{6}{|l|}{$\begin{array}{l}\text { 4. To complement the Missouri S\&T Mission Statement, to what } \\
\text { extent does the Fraternity and Sorority Life Office: }\end{array}$} \\
\hline $\begin{array}{l}\text { a. Promote the intellectual, social, spiritual, moral, civic \& career } \\
\text { development, and wellness of students }\end{array}$ & 4.17 & 3.97 & 3.97 & 4.18 & 4.02 \\
\hline $\begin{array}{l}\text { b. Provide education \& experience in leadership, group dynamics, } \\
\text { and organization development }\end{array}$ & 4.25 & 4.09 & 4.17 & 4.00 & 4.13 \\
\hline c. Promote student involvement in co-curricular activities & 4.33 & 4.03 & 4.14 & 4.00 & 4.11 \\
\hline $\begin{array}{l}\text { d. Promote sponsorship of and participation in community service } \\
\text { and philanthropic projects }\end{array}$ & 4.17 & 4.23 & 4.25 & 4.09 & 4.21 \\
\hline $\begin{array}{l}\text { e. Promote an appreciation for different lifestyles including cultural } \\
\text { and religious heritages }\end{array}$ & 4.00 & 4.00 & 3.94 & 4.18 & 4.00 \\
\hline $\begin{array}{l}\text { f. Recognize and encourage the positive learning experiences that } \\
\text { are possible in a fraternity and a sorority community that has a } \\
\text { diversified membership }\end{array}$ & 3.75 & 4.20 & 4.03 & 4.27 & 4.09 \\
\hline $\begin{array}{l}\text { 5. To what extent does the Fraternity and Sorority Life Office } \\
\text { promote Greek communities as being integral to Missouri S\&T }\end{array}$ & 4.08 & 4.12 & 4.33 & 4.00 & 4.11 \\
\hline
\end{tabular}




\section{Focus Group Discussion Summary}

I conducted two focus groups. One group was comprised of volunteer student leaders, and the other group was made up of Greek alumni volunteers. Eight Greek leaders agreed to participate in a student focus group discussion. Of these participants, seven were male and one was female. All the student participants were current, newly elected, or immediate past chapter presidents. Four alumni (one female and three males) of the approximately 50 Greek alumni agreed to participate in an alumni discussion. The invited alumni were persons who are currently engaged with the Fraternity and Sorority Life Office as well as with their respective chapters. Each of the alumni who agreed to participate in a focus group discussion holds an office in one of their chapters' alumni organizations and each graduated from Missouri S\&T prior to the year 2000. Three of the alumni participated in person in this focus group discussion and one participated via conference call.

The thematic data groups reflecting clusters of focus group comments were deductively aligned by topic with the survey findings. They have been used in this capacity to triangulate with and help interpret the survey's findings. In most circumstances, particularly involving student focus group data, the focus group comments lent credence to the survey question findings; however, in some circumstances the focus group data did raise questions regarding the credibility of the survey findings. Within the topic areas, it was relatively simple to demonstrate student consensus because the student survey data concurred with nearly all data collected in the focus group.

The alumni participant perspectives concurred less often with the survey findings than did the student participant perspectives. This was not surprising because only current Greek students responded to the survey and the Greek alumni were not asked to complete 
the survey. Further, similar to findings reported in other Greek life studies involving both students and alumni (Jelke \& Kuh, 2003; Koepsell, 2008), the alumni participants' perspectives were less uniform than those of the student focus group so fewer consensus observations able to be drawn from the alumni focus group discussion.

\section{Aligned Survey and Focus Group Findings}

The combined survey summary and accompanying focus group findings are discussed below. Exemplar quotes highlighting the common participant sentiments in both discussions are included in text boxes throughout the narrative.

Category 1: Understanding of the Purpose of the Fraternity and Sorority Life Office

The first survey question asked participants to indicate how well the Greek community members understood the purpose of the Fraternity and Sorority Life Office. The mean score (3.77) was the lowest average response from the survey participants. It was the only survey question with an overall mean below 4.00 (good/criteria well "I knew we had a Greek Office, but I looked at IFC as the people to go to who could represent us if something were to go wrong or for guidance."

Fraternity Chapter President met) on this survey's five point scale.

The focus group discussion comments related to this first question generally reflected participants' confusion or uncertainty regarding the purpose of this Office. However, one role of the Office was perceived more clearly. Both the student and the alumni participants regard this Office's primary function as being the University's enforcement agency that exercises some control over the Greek chapters.

Student focus group participants noted that within the Greek community, this Office was perceived as not being committed to advancing the welfare of the chapters. Instead, they felt that this Office's priority was to advance the University's interests 
within the Greek community. The student participants did indicate that they felt the current Fraternity and Sorority Life Program Coordinator and the Director of Student Life were "different" from their predecessors and that both these staff members showed an interest in the Greek chapters that was not seen among their predecessors. The students observed that these two staff members have contributed to changing some officers' perceptions but they did not believe that this change was reflected among most of the Greek population.

The alumni participants held an even more negative opinion of this Office than did the students. The alumni not only considered the Fraternity and Sorority Life Office to be disinterested in the chapters' interests, but also considered it to be an impediment for their chapters. This group felt that their chapters would be more successful if this Office would "get out of their way and stop making report and compliance expectations of the chapters." The alumni agreed that most of the University requirements or expectations for Greek chapters represented obstacles. This group also considered the Fraternity and Sorority life Office to be the University's mechanism for imposing those obstacles on the chapters. One alumni group participant also suggested that if the Fraternity and Sorority Life Office wanted to serve the chapters, it should reverse its efforts and become the Greek Community's lobbying agent for University support. Category 2: The Fraternity and Sorority Life Office's Compliance with the CAS

\section{Standards}

Participants were asked three survey questions regarding their perception of the Fraternity and Sorority Life Office's compliance with the CAS Standards for Fraternity and Sorority Advising. The mean responses for each of these three questions ranged from 4.0 to 4.24 and the differences between these means are not great enough to be 
considered significant. Overall, these scores suggest that the survey participants generally perceived the Fraternity and Sorority Life Office as effectively meeting each criterion of these CAS expectations.

The focus group discussion comments related to these three questions were tangential. When looked at narrowly, the students generally reinforced the survey results. For example, students identified a number of activities sponsored by the Fraternity and Sorority Life Office and would describe how the Office encouraged Greek students to participate in campus activities that advanced their academic success or their individual development.

However, the students' comments also indicated that they did not see much value in these activities. One student reflected that too often "(When I joined my chapter) Ifelt like the consensus from the older members and leaders in the house was that the Greek Office use to be fairly ineffective and wasn't taken very seriously."

Fraternity Chapter President/Elect University activities are planned without considering details such as what might be the best times for scheduling these activities and whether these program activities are even desired by students.

When asked why these questions received favorable responses if the program efforts were not valued, students indicated that it was the manner in which the survey questions were stated. The questions, as they were worded, asked the students whether this Office complied with the CAS Standards. The participants' perspective was that this Office does comply with those standards. What the survey did not ask respondents whether compliance with the CAS Standards had any relevance with the Greek community's expectations of this Office. Those in the focus group felt that compliance with the CAS standards was of little consequence. Moreover, participants reflected that 
the much of the Greek community is not sufficiently familiar the CAS Standards, or their purpose, to understand how they would have a bearing on a Greek chapter's objectives.

Category 3: The Extent of Fraternity and Sorority Life Office Programs Consistency with the Missouri S\&T Mission and Values

The mean average for all responses regarding the extent to which the Fraternity and Sorority Life Office implements programs and services are consistent with Missouri S\&T's mission and values was 4.30. This question had the highest mean average response from the survey participants.

Information provided by both focus groups helped interpret this score. The student focus group suggested that the strength of this average could be attributed to a long-standing perception that the Fraternity and Sorority Life Office's purpose is to ensure that the Greek chapters comply with University policies governing approved student housing. The alumni group made similar assertions, but also indicated that by prioritizing consistency with the University mission sometimes diminishes the worth of this Office to the Greek chapters.

That the Fraternity and Sorority Life Office's programs closely align with the University's interests was a discussion topic for which the alumni group provided some of their

"I like the dialog we (Greek community /Greek Life Office) have; there is probably room for advancement. But don't push too hard, like the GPS (Greek Plan for Success) it seemed like too much all at once. There is room for improvement but don't push mandatory stuff on us all at once."

Sorority Chapter Immediate Past President most poignant comments. None of the alumni participants suggested that this Office ought to be in conflict with Missouri S\&T's values but they did not see it as being necessary to always be aligned with the University in order to fulfill the alumni 
expectation of service to the Greek chapters. One alumnus commented that clarified the group's perspective was that chapter objectives sometimes contradicted University's objectives so always strongly aligning itself with the University's interests, this Office is not able to function as a resource for the chapters. When asked if this was meant to suggest that the Fraternity and Sorority Life Office should operate in ways that conflicted with University policy, another alumnus that the Fraternity and Sorority Life Office could potentially better serve the Greek community if it acted more often as a mediator during times of difference between the Greeks and the University.

Category 4: The Extent that the Fraternity and Sorority Life Office Complements the Missouri S\&T Mission

Six survey questions asked participants for their perception about the extent to which the Fraternity and Sorority Life Office programs complement the Missouri S\&T mission. The mean responses for each of these six questions ranged from 4.0 to 4.21 and the differences between these means were not great enough to be considered significant. Overall, these scores suggest that each criterion is being well met by the Fraternity and Sorority Life Office.

The focus groups did not directly address the synergies between Greek community programs and the

"Good things are happening in the Greek houses not because of the University helping you but because you are doing it on your own." Fraternity Chapter President University mission. However, participants did suggest that this Office's activities supported the University mission. The participants also acknowledged that this Office sponsors program activities for Greek students and endorses Greek student participation in various campus programs. 
Little was said in either focus group regarding whether the Office's program efforts to support the University mission were also effectively contributing to the University achieving its mission. Also participants in both groups questioned whether the Fraternity and Sorority Life Office places too much of a priority on aligning itself with the University's mission rather than on serving its clients' needs. These participants did not suggest that this Office's efforts should not align with the University's mission but indicated that more consideration should be given to client needs, irrespective of whether or not they align with the University's mission.

What might explain this theme's high survey scores was that, like other questions, the participants narrowly interpreted the questions. This suggests that the perceived effort by the Fraternity and Sorority Life Office to align itself with the University's mission is also seen as the Office primarily endeavoring to complement University mission.

Category 5: The Extent that the Fraternity and Sorority Life Office Promotes Community

\section{Development}

Question five focused on the extent to which the Fraternity and Sorority Life Office promotes Greek communities as being integral to Missouri S\&T. This question's mean average of 4.11 suggests that this expectation is being well met.

However, the alumni focus group disagreed with the student leaders' survey results. One alumnus suggested that the University and its Greek Community "co-exist" with each other. Their sense was that while both entities share a common constituent group of students, staff, faculty and alumni, the purposes served by the University and the Greek community are not connected. According to the alumni, Missouri S\&T and its Greek community functioning in parallel environments with the chapters' objectives primarily reflecting the expectations of their national organizations and not the 
University's expectations. Further, the alumni were comfortable with this arrangement and did not have any compelling reason for this relationship to change.

The student focus provided some insight into the relative strength of the survey data. Similar to the alumni observations, the students indicated that the chapters are motivated to achieve their objectives to receive national recognition for contributing to the goals of their national fraternity or sorority. The students also felt that chapter involvement in University events is seldom inspired by the opportunity to better the

"There are certain instances where our national's expect certain things from us and are completely ok with it, but when we try to do it on this campus sometimes Student Life and Greek Life put a bar on it and they say you can't do that"

Fraternity Chapter President University community. Rather, Greek chapter involvement in campus activities most often occurs when chapters believe that their participation may either aid a chapter in achieving recognition awards from their national organizations (e.g., campus sponsored community service and campus sponsored risk management or leadership training) or if their participation may help a chapter's ability to recruit new members (e.g., campus ambassadors, new student programs).

During the course of their discussion, the students repeatedly referred back to the current Fraternity and Sorority Life staff members and spoke favorably about their efforts to engage with the officers and to provide them with useful campus activity information. While these staff members' efforts to advise the Greek officers and governing organizations were portrayed in a favorable light, this effort did not translate for the student participants into a meaningful contribution to the Greek community. 
Category 6: Emergent Themes and Pertinent Focus Group Comments

There were some relevant focus group discussion themes that did not directly relate to any CAS themes. These comments are summarized here since they may have some potentially valuable information that could assist the Fraternity and Sorority Life Office in it future goal setting or program planning exercises.

Chapter leaders focus group comments. At different points during the student focus group, a number of comments were made expressing appreciation and respect for Brett Watson, the Fraternity and Sorority Life Office Coordinator. The students seemed to go out of their way to ensure that their sentiments for Mr. Watson were mentioned in the discussion. They shared that Mr. Watson was someone who was genuinely concerned about them and their chapters.

"One thing that my presidency is doing is getting (the chapter) back to their values and Brett is really passionate about that and has been helping me out with different activities."

Fraternity Chapter President They also expressed their appreciation for his efforts to work with chapter presidents who were having difficulty coping with chapter issues. Similar comments were also directed toward Mr. Watson's supervisor, Angela Perkins, the Director of the Student Life Department. The occasional assistance provided to the Greek chapters by the Vice Chancellor for Student Affairs Office was also mentioned favorably.

The students were asked why they provided such favorable comments regarding the University staff affiliated with Fraternity and Sorority Life while their perceptions of the Fraternity and Sorority Life Office were mixed. The students indicated that the staff members are good people who care about the students and who are good to work with on 
a one-on-one basis. However, the Greek students did not see many of the Fraternity and Sorority Life Office activities as being very helpful in supporting the chapters' interests.

While student leaders' perceptions of the Fraternity and Sorority Life Office as an asset for their chapters remains relatively low, this study's findings do reveal that the working relationships between the Greek officers and the Fraternity and Sorority Life staff is stronger "If Student Life could present tools to help fraternities tap that market or provide guidance that would be an area of improvement."

Fraternity Chapter President/Elect now than in past years. This represents a positive trend that should be encouraged to grow, as continued efforts have the potential to extend beyond personal relationships to include the organizations. If this outcome can be achieved, it would help to develop more credibility for this Office among the chapter leaders and future alumni.

Alumni focus group comments. The nature of the relationship between the Fraternity and Sorority Life Office and the Greek chapters was a point of contention for the alumni participants. This group generally held the perspective that the Fraternity and Sorority Life Office's near exclusive priority should be to aid the chapters. This group felt that a priority for this Office ought to be to find remedies when there are conflicts between the University and the Greek community that, if unresolved, impede the chapters' abilities to achieve their objectives.

One alumnus provided an example of such a perceived conflict. He shared that the University policies mandated by the Family Education Rights and Privacy Act (FERPA) mandated policies unduly restricted chapter access to student information. This alumnus felt that these University FEFPA guidelines governing access to student information hindered his chapter's new member recruiting efforts. He also felt that rather than taking the stance of attempting to educate the Greek chapters about the parameters under which 
the University can release student information to them, the Fraternity and Sorority Life Office should be the Greek community's advocate in this matter and lobby the University administration to modify its operating policy in a way that would give its Greek chapters greater access to this student information.

The alumni participants seemed interested in what opportunities there might be for the Fraternity and Sorority Life Office to help their chapters. While the alumni feel strongly the chapters' ambitions do not necessarily have to complement those of the University, this group is willing to talk about how to improve this Office. Future discussions such as these could possibly be used to cultivate a stronger relationship between the Fraternity and Sorority Life Office and the Greek alumni.

Implications, Limitations, and Recommendations

This evaluation of the Missouri S\&T Fraternity and Sorority Life Program explored perceptions held by this office's primary clients regarding the extent to which its program activities align with the CAS Standards. The findings of this study have implications for the Fraternity and Sorority Life Office, the Student Life Department and Missouri S\&T.

While the survey's design provided participants with little opportunity to deviate from providing their input on its five themes, both focus groups engaged in discussions that went beyond the topic themes, to focus on chapter relationships with this Office. Specifically, participants were interested in discussing this Office's role as a Greek chapter advocate. This in itself was a significant finding as it reflects a tension between the University's intention for maintaining a Fraternity and Sorority Life Office and the Office's clients' perspective regarding what ought to be its purpose. This is a dynamic that overrides the other implications drawn from this study. This lack of a common 
understanding of this Office's purpose connects to almost all other concerns voiced about this Office's programs and services.

The Purpose of the Fraternity and Sorority Life Office

To a great extent, study participants are not convinced that Missouri S\&T needs a Fraternity and Sorority Life Office. Skepticism as to whether a Fraternity and Sorority Life Office has a meaningful purpose within a campus community has often been mentioned as a primary reason for reviewing its programs (Gregory, 2003). What differs in this study in relation to other Greek studies (Gregory, 2003; Jelke \& Kuh, 2003) is that in addition to this skepticism is that there is no generally recognized statement delineating the purpose of this Office. Determining a clearly understood and generally agreed upon purpose for the Fraternity and Sorority Life Office should be a significant and immediate priority. Without such a statement, this Office's stakeholders cannot know what programs or services it can be expected to provide. Identifying a purpose for this Office that reflects contributions from its stakeholders will also provide the parameters for future performance measures.

The Mission of the Fraternity and Sorority Life Office

This past spring, the Missouri S\&T Fraternity and Sorority Life Office Web did add a Greek Life banner statement on its web site stating; "Missouri S\&T Fraternity \& Sorority Life is committed to creating a positive, values-based fraternal experience by providing first class leadership, educational, service, and social opportunities that complement the University's educational mission." This study's focus group participants were provided this statement but no one recognized it, nor did anyone recall seeing any similar statement pertaining to the Fraternity and Sorority Life Office. However, the study participants concurred that this statement did describe activities that ought to and 
often do occur in the Missouri S\&T Greek chapters. That the focus group participants did not recognize that the Fraternity and Sorority Life Office's programs either are or should contribute to the traits mentioned in the web site statement is another suggestion that this population lacks an understanding of why this Office should even exist.

Like a clear purpose statement, this Office does not have a mission that is readily recognized by its stakeholders. Such a statement is the essential first step needed to begin to educate these clients as to why this Office exists.

\section{The Significance of the Fraternity and Sorority Life Office}

Another aspect revealed by this study's findings is a perception that the Fraternity and Sorority Life Office is not a significant contributor to the Greek community environment. While the student participants indicated that this Office's programs did contribute to the quality of the Missouri S\&T Greek community, particularly if chapter participated in programs that aligned with national priorities and could result in recognition by these national offices, this Office's program efforts were not considered to be major influences in the Greek community. While this Office states that its intent is to help enhance the campus Greek community as well as the experiences of its members, findings from this program evaluation show that this community's leaders consider this Office's primary function is to be the University's mechanism for assuring Greek chapter compliance with University policies.

\section{Alignment of the Fraternity and Sorority Life Office Goals and Objectives}

The Fraternity and Sorority Life Office will need to establish goals that consider the needs of its client groups, the policy expectations of Missouri S\&T, state, and federal governments, and national association expectations of the various local chapters. To do so, more information is needed to better understand how this Office can comply with the 
University's mission and values, while also effectively supporting the Greek chapters in ways perceived to be valuable by stakeholders.

Because client needs were not investigated by this study, I learned little about them. Thus, an inquiry into client needs is warranted to better guide the efforts of this Office. Because the national fraternal organizations' expectations were also not investigated by this study, little understanding was gained about their expectations of the Missouri S\&T chapters. However, because the chapters display a propensity for aligning their objectives with national expectations, it may be reasonable to expect that these objectives will be reflected in an inquiry into client needs. In addition, a Fraternity and Sorority Life Office goal setting exercise that involves the Office staff and a representative client group might provide an opportunity to better connect chapter needs, the University's expectations, and national fraternal organization expectations.

Future Use of CAS Standards as a Fraternity and Sorority Life Performance Standards

I used CAS Standards for Fraternity and Sorority Advising as this study's performance standard. These standards were being used with a population that had several members who were either unfamiliar with them, or if familiar with the CAS Standards, had not used them evaluative purposes. Efforts similar to those employed in other university Greek Life evaluations (Bureau, 2007) were made to educate the survey and focus group participants regarding the CAS Standards and their purpose in this study. However, the inconsistencies between the survey results and the focus group findings, along with comments made during the focus group sessions, suggest that the instructions and material that were provided did not adequately familiarize some participants with the standards. Jelke (2001) and Bureau (2011) noted similar findings, despite other studies that have successfully used these materials (Gregory, 2003). The result was that 
participants' familiarity with the performance measures may have had a bearing on the credibility of this study's findings. However, multiple data sources (survey and focus groups) did mitigate some concern.

More consideration is needed regarding the use of CAS Standards prior to attempting a similar application within the Missouri S\&T campus community. This study's findings suggest that prior to their use with the Missouri S\&T students, a better strategy is needed for preparing students to apply them within the desired context of a study.

The data from focus groups suggested that the survey participants tended to strictly interpret its questions. If the participants had interpreted the survey questions less literally and more from the context of how its questions relate to the Missouri S\&T campus environment, this study's survey instrument may have produced some significantly different information (e.g., If the stated purpose of a given Fraternity and Sorority Life Office program was considered to be aligned with a CAS Standard, participants tended to consider this to display compliance. No suggestion was made to the participants that compliance also requires that an activity actually makes a desired contribution to the Greek community).

The survey participants' lack of familiarity with the CAS Standards and their use to measure program effectiveness diminished survey's worth as a performance measure in this program evaluation. Before the CAS Standards are used again as a performance measure in an evaluation of a Missouri S\&T support program, their method of application needs to be reconsidered. I presumed that the successful use of the CAS Standards instrument in reviews on other campuses was evidence they would be an effective program review performance measure for this study (Bureau, 2011). However, this study 
demonstrated that the means used to apply the CAS Standards are not universal. Further, the instrument may be useful for student affairs professionals to consider performance issues, but for students at Missouri S\&T, I did not learn as much about the Greek Life Office as I might have if I had used an instrument that measured the standards through examples that directly applied to students. For example, on a scale from $1-5$, rate the degree to which you were aware of programs offered by the Greek Life Office for chapter members; rate how these programs got you more involved on campus and in the community. Either adaptations are needed that are based on the specific application of the CAS standards or the CAS Standards value as a performance measure is not as universal as the literature review (Appendix C) conducted for this study has suggested.

Conclusion

This program evaluation of the Missouri S\&T Fraternity and Sorority Life Office's compliance with the CAS Standards for Fraternity and Sorority advising is expected to help this office and its parent department better understand its stakeholders' expectations and the perceived performance of this office's programs and services. Findings show that participants did not have a good understanding of the purpose of the Missouri S\&T Fraternity and Sorority Life Office. While participant ambiguity in their understanding of the Fraternity and Sorority Life Office's purpose is an overarching issue in this study, the findings do contain useful information for this office to consider as it develops its goals and strategic plans. These findings will also influence decisions regarding the design, implementation, and evaluation of future programs. While this evaluation's findings may not be applicable to other settings, this study may serve as a model to use when developing program evaluations for other Missouri S\&T Student Affairs departments or offices. 
A future evaluation of the Fraternity and Sorority Life Office will need to be more comprehensive than was this. Such studies should consider incorporating means to assure that participants understand the purpose of the study. Also any data gathering instruments should be thoroughly pre-tested for their ease of understanding by participants and for common understanding between the investigators and all the participants regarding the purpose for conducting an effective and useful evaluation. 
Appendix A

\section{ORGANIZATION CHART}

Missouri S\&T Student Affairs Division;

Student \& Community Development Area

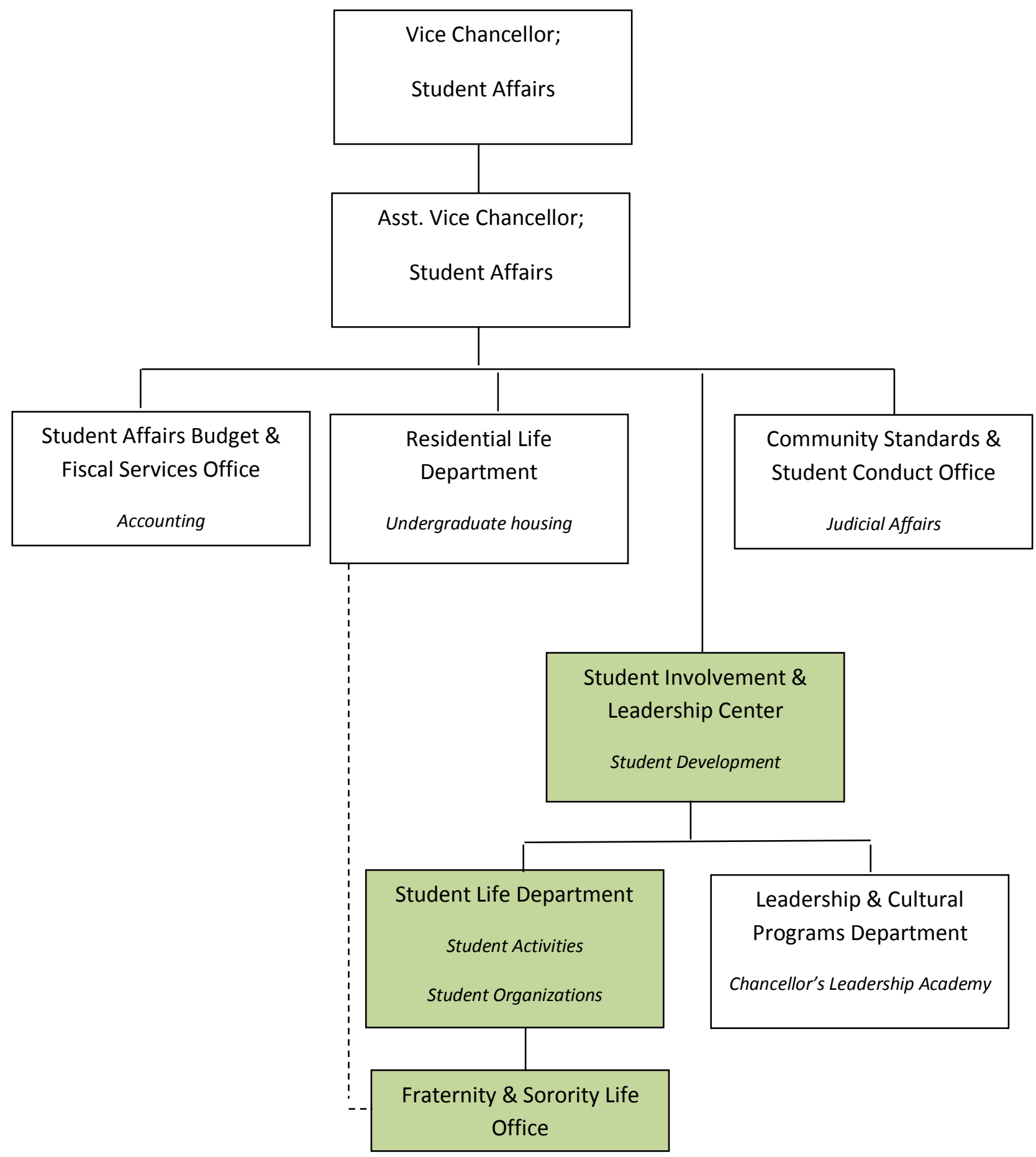


Appendix B

\section{METHODOLOGICAL APPROACH}

Introduction

This program evaluation was an exploratory, improvement oriented, formative study. My interest in conducting this study lies in its potential to gather client perceptions of the Fraternity and Sorority Life Office. My purpose for gathering this information was to provide this Office with information about its clients' perspectives regarding its programs and services that can be used to develop program improvement goals. In this study I collected information, by investigating this question: How effectively do the Missouri S\&T Fraternity \& Sorority Life Office clients feel this Office complies with the CAS Standards for Fraternity and Sorority Advising?

This study's purpose was not to answer a hypothesized question; instead, its purpose was to investigate a problem that was not well understood (Creswell, 2003). This study is considered to be formative because it collected data that can be used to modify or to improve a program rather than to measure an outcome or result (Shepard, 2005).

The framework that guided the design and application of this program evaluation is Michael Patton's (1997) utilization focused evaluation model. Patton's utilization focused evaluation model emphasizes that an evaluation's design should focus on accomplishing an intended use rather than on conforming to a particular research method.

\section{Rationale}

Exploratory research methods are characteristically flexible due to the ambiguity of the problems they are used to investigate. Exploratory research can adapt various research methods (Shields \& Hassan, 2006) according to which one appears to offer the best likelihood of collecting desired information (McQuarrie, 2006). Because no 
particular research methodology is associated with exploratory studies, the researcher is able to exercise some discretion in identifying methods (Bryman, 2002).

Using a rationale based on a methodological framework already considered to be credible in similar applications can give legitimacy to a researcher's selection of a method (Bryman, 2002; Creswell, 1998; Mable, 1991). My choice of methods for this study reflects Locke's observation that "the adequacy of a research method depends on the purpose of the research and the questions being asked" (cited in Seidman, 1998, p. 5) as well as Patton's (1997) contention that conducting effective research requires an evaluator to focus on determining the best available method for collecting useful information. For this program evaluation case study, two research methods, a survey and focus groups, were selected based on their demonstrated applicability to exploratory studies (Bryman, 2002) as well as the fact that both are relatively easy to acquire and simple to implement.

\section{Case Studies}

Patton (1997) asserts that "There is no one best way to conduct an evaluation ..... the design of a particular evaluation depends on the people involved and their situation" (p. 126). The intention of this evaluation has been to learn about the Missouri S\&T Greek chapter leaders' and Greek alumni's perceptions of the programs and services provided by the Missouri S\&T Fraternity and Sorority Life Office. Because there are no performance measures in place to measure its stakeholders' satisfaction (Kennerley \& Neely, 2002) with its programs, this poorly understood problem was studied through descriptive and contextual analysis. This study precedes a more comprehensive study, thereby serving as a pilot project to help develop protocols to be used to conduct more extensive evaluations (Yin, 1994). 
A case study offers the opportunity to maximize what can be learned within a limited amount of time (Stake, 1995). Its effectiveness is also affected by the practicality of studying a topic and the willingness of its subjects (Stake, 1995; Yin, 1993).

Determining the Missouri S\&T Fraternity and Sorority Life Office's compliance with performance standards is an area of interest and of concern for both the researcher and the participants, justifying the need for a study.

Case study design focuses on the uniqueness of individual situations and requires the application of research methods that are best suited to study that problem (Stake, 1995; Yin, 1994). In this case, both descriptive (quantitative) statistics and focus groups (qualitative) will inform the study. This utilitarian perspective is also acknowledged in the nature of the program evaluation (Jelke, 2001; Morgan, 1993; Yin, 1994).

This case study design is dictated by function. The Fraternity and Sorority Life Office's parent organization and its stakeholders both expect this Office to demonstrate that its programs' outcomes contribute to it meeting an accepted set of expectations. However, while theory has not dictated this case study's design, Patton's (1997) utilization focused evaluation model guided the aspects of its design (Stake, 1995), particularly the research questions posed, the data collection techniques, and the analysis of the data.

\section{User Participation}

A utilization focused evaluation will characteristically have its evaluator facilitate a certain level of decision-making by the intended users into the design and use of the evaluation (Jelke, 2001; Patton, 1997). This practice stands in contrast with most traditional research models where the evaluator acts independent of the study's users (Patton, 1997). The purpose for this type of evaluator/user relationship is to encourage a 
feeling of ownership with the users and to diminish users' fears of evaluation. In this study, because of the evaluator's relationship to the program, involving the users has an additional benefit. The users' insights into this evaluation's design and application also help mitigate user apprehensions regarding the evaluator's intention in conducting this study (Jick, 1979; Patton, 1997; Stake, 1995).

The first step in engaging users when conducting a utilization focused evaluation is to determine the primary intended users of the results. In this study, the intended users were the persons who will determine the goals for the Fraternity and Sorority Life Office. For this reason, the Student Life Department administrative staff was kept informed of the purpose, the intent, and the progress of this study. They were provided periodic updates during group and individual meetings with me and their suggestions were encouraged. Their feedback was also welcomed if they became aware of any related client concerns. Assurances were given the Student Life Department staff that this study will not be used to measure personnel performance (APPENDIX E). The second step is for the evaluator and the intended users to agree on the uses of the evaluation and then determine its focus. For this study, we agreed that the findings of this evaluation will contribute to the basis for establishing organizational goals.

\section{Participants}

Data was collected from two different population groups. One population group consisted of the active Greek students. The second group consisted of Greek alumni who continue to be actively involved with their undergraduate chapters in capacities such as serving as an alumni association or housing corporation officer, regularly contributing to chapter fund-raising activities, or regularly attending chapter sponsored, alumni events. 


\section{Selection of Participants}

In this study I used two sampling methods, convenience and purposeful, to select participant groups. Convenience and purposeful sampling are similar but not identical sampling methods. In both methods, samples were not randomly chosen, nor were attempts made to obtain a sample that reflects the population (Patton, 1990). Both methods have a likelihood of collecting input that reflects the sentiments of a target population, but the non-randomness of both sampling methods left open the possibility of this study having subgroups that over represented, under represented, or entirely omitted useful input from other sub-groups (Neuman, 1997).

The following were the advantages of using both convenience and purposeful samples in this study:

- They were easy to carry out because few rules govern how the sample should be collected.

- The time and resources required to carry out either sample was small in comparison to those usually needed in a probability sampling technique. This enabled me to achieve the sample size I want in a relatively fast and inexpensive way.

- Both methods helped me gather useful data and information that would not have been possible using probability sampling techniques, which require more formal access to lists of populations (Heppner \& Heppner, 2004).

The primary difference between purposeful and convenience sampling is that in a purposeful sample, one or more specific predefined groups are sought out (Trochim, 2006), rather than choosing participants simply through ease of access, as is done in convenience sampling. The goal in selecting a purposeful sample for this study was to 
select those who have a similar interest that best helped the researcher to answer the study's research question (Patton, 2001).

Both sampling methods also contrast with probability sampling, where the selection of participants is done randomly and with the intention of creating a pool of participants who will be a representation of a larger population (Patton, 1990). For the purposes of this study, a representative sample population was not required. Collecting information that likely represented the larger population's sentiments may have been desirable but without a hypothesis to test, proving the probability that the population sample was a representative sample was not essential (Heppner \& Heppner, 2004).

Greek student leader participant selection. Greek chapter leaders' participation in this study had a significant bearing on the worth of this study's findings. Other Greek life program reviews, noted the value of involving the Greek chapter leaders (Brown, 2007; Callais, 2002; Jelke, 2001) since among all the active chapter members, chapter leaders represented the clients who most often access a campus Greek Life Office. So, while other Greek population groups may provide useful information, the chapter leader perspectives are generally considered to be critical (Whipple \& Sullivan, 1998).

For this study, Greek student leaders were the elected fraternity and sorority chapter officers. There are approximately 150 active chapter officers from the 24 Missouri S\&T Greek chapters in this population. This convenience sample was desirable for several reasons:

- This was a preliminary investigation that targeted interested in participants who are familiar with the Fraternity and Sorority Life Office.

- This was a readily accessible sample group. Chapter officers comprise a subgroup that is accessible. They regularly meet as groups and individually with the 
Fraternity and Sorority Life Office, and they regularly interact on their own email list serves.

- At the time this study was conducted, there was no regular mechanism to collect data from Missouri S\&T Greek students. Beginning with a small, similarly invested group of officers who are relatively easy to contact allowed for a stronger likelihood of participation.

- The Missouri S\&T Greek officers have traditionally expected themselves to be the spokespersons for their chapters and the Missouri S\&T Greek community. Distributing a survey instrument to all active Greek members would have likely been perceived by many officers as a violation of this unwritten spokesperson trust. If there was a perceived violation of this officer trust, it would have likely reduced officer participation.

Alumni participant selection. The number of active Greek alumni is unknown. However, there are approximately 50 Greek alumni members who have their contact information on file with the Fraternity and Sorority Life Office. These alumni have an expressed desire to be informed about the campus Greek community or their chapter. In addition, many of these potential participants are regularly invited to and participate in the University sponsored, bi-annual Greek alumni discussions. This sort of involvement may mean they would be more willing to participate in this study. In this context, I used a convenience sample of alumni who have contact information on file at Missouri S\&T.

\section{Procedure for Collecting Data}

Both qualitative and quantitative methods are frequently used to collect client information, but each represents a different research approach; one is a positivist approach and the other is an interpretivist approach (Denzin \& Lincoln, 2000; Patton, 
1997; Tyler, 1980). For this study, the decision was made to combine these methods. This reflects Patton's (1997) notion that research should be designed with the emphasis being on accomplishment over conformity. The methods used in this study for gathering and analyzing data were intended to result in findings that are useful and informative (Preskill $\&$ Torres, 1999). Following a prescribed approach for the sake of conforming to an established method is of little value if it doing so does not generate applicable results (Patton, 1997; Yin, 1994).

The integrity of this study's design relied not only on the endorsement of Patton (1997), but of several others who encourage using both quantitative and qualitative methods when conducting formative evaluations (Bullock \& Ory, 2000; Fraenkel \& Wallen, 2003; Preskill \& Torres, 1999). In many circumstances, multi-method research has become the preferred among educational researchers when conducting program evaluations (Bullock \& Ory, 2000).

Two research instruments were used to collect data. One instrument was a survey that gathered primarily quantitative data (Appendix C). The other instruments were the focus group protocol (Appendix D) and the researcher.

\section{Survey}

This survey’s purpose was to ask participants to assess the Missouri S\&T Fraternity and Sorority Life Office program's compliance with the CAS fraternity and sorority advising program criteria. One population, the Greek leaders used a survey instrument. This survey incorporated elements of the CAS Fraternity and Sorority Advisor Standards, and its design was modeled after the CAS Fraternity and Sorority Self-Assessment Guide. For each criterion, participants were asked to use a five-point scale to evaluate the office's compliance. The participants were also asked to provide 
short-answer responses to three questions pertaining to the Fraternity and Sorority Life Office's mission and purpose.

The participants' contact information was accessed through the Fraternity and Sorority Life Offices. An initial announcement that this study was being conducted (Umbach, 2004), its purpose, and a request for participant involvement were made to the chapter Presidents and the other chapter executive officers during the April monthly Greek President's meeting. A similar announcement was emailed with an attachment that explained the study in greater detail and gave instructions on how to access the survey instrument.

The surveys were distributed on-line using Qualtrics. No names or identifying marks were requested and completed surveys were returned to me in a format that allowed tracking of who responded but did not allow responses to be linked to participants.

Response rate is the single most important indicator of how much confidence can be placed in the results of a survey and one of the most effective tools for increasing response is the use of follow-up reminders (Field, 2005; Heppner \& Heppner, 2004; Merriam, 1998). Email contacts were made with the non-responding participants 5 days, 8 days and 12 days after the survey was distributed (Umbach, 2004). These email reminders asked them again to complete and return the survey instrument. These reminders also again provided link access to this online survey.

There were 148 survey questionnaires sent to the Chapter officers. When the survey closed, 47 completed surveys had been returned. 


\section{Focus Groups}

The focus groups provided this study information such as participant reactions to others' responses, open-ended responses that built upon other comments and non-verbal messages that could not be collected through this study's surveys (Hogan, 2007; Yin, 1993). Specifically, focus group discussions allowed participants to listen to others' verbalized experiences, and by doing so, often stimulated their own memories, ideas, and experiences (Yin, 1994). "This is also known as the group effect where group members engage in a kind of 'chaining' or 'cascading' effect; talk links to, or tumbles out of, the topics and expressions preceding it" (Lindlof \& Taylor, 2002, p. 182). I conducted two focus groups. One group was comprised of volunteer student leaders, and the other group was made up of Greek alumni volunteers.

Participation. The first 12 Greek presidents who returned surveys and indicated their interest in participating in a discussion group were invited to participate in one of this study's focus group discussion. From this group, eight agreed to participate in a focus group discussion. Of these participants, seven were male and one was female. All the participants were current, newly elected or immediate past chapter presidents.

Oral and written invitations to participate in a focus group discussion were extended to each of the 19 Greek alumni who attended a spring Greek Life information meeting. Only four alumni, one female and three males, agreed to participate in a focus group discussion. Each of these participants held offices in their chapters' alumni organizations and each had graduated from Missouri S\&T prior to 2000.

Format. For both focus groups, I began by asking participants to introduce themselves. Their introductory remarks initiated a discussion by having group members respond with their experiences with the general topic of the focus group (Krueger \& 
Casey, 2000). Next more specific questions were asked that solicited their perceptions of Greek Life at Missouri S\&T. Both focus group discussions lasted about 75 minutes.

The audio portions of both session sessions were recorded with the participants' consent. This common technique for collecting focus group information (Krueger \& Casey, 2000; Yin, 1993) provided an accurate account of what is being said within a discussion. Another Missouri S\&T student affairs professional staff member not affiliated with the Fraternity and Sorority Life Office, volunteered to assist in conducting the focus group discussions. This staff member and I, also both noted non-verbal activities that were observed (Krueger \& Casey, 2000). The audio recordings of the completed session were then transcribed verbatim into a written narrative by an experienced, independent transcriptionist.

Researcher. The concept of the researcher as a routine collection instrument is prevalent in qualitative literature (Denzin \& Lincoln, 2000). It has become expected that the researcher is one of a study's data collecting instruments and that its primary evidence and findings are interwoven with the researchers reasoned interpretation of the phenomenon (Creswell, 2003; Denzin \& Lincoln, 2000; Thurmond, 2001).

Qualitative researchers seek to understand the phenomenal world through the study of events, actions, talk, and interactions. Denzin and Lincoln (2000) characterize the interpretive nature of qualitative inquiry by explaining that "qualitative research is a situated activity that locates the observer in the world. It (a qualitative inquiry) consists of a set of interpretive, material practices that make the world visible" (p. 3). Thus, as a qualitative researcher, I too contributed to this study's data by making observations of the focus group sessions and their participants. 
Further, the data recorded for this study has been organized and analyzed by me and this study's conclusions are based on these findings. In doing so, my perceptions and ability to elicit findings from data details has influenced the findings. This also introduced my knowledge, experience, and perspective into this study. Therefore, the findings include the relative merits and potential limitations that my knowledge, my perspective, and my subjectivity contribute to this study.

Procedure for Analyzing Data

I analyzed and summarized the data collected from all sources independently. Then I related these findings with each other using a form of methodological triangulation (Bryman, 2002). This form of data interpretation follows a variation of triangulation described as a convergence model (Creswell, 1999). Triangulation enhances the credibility of the findings (Creswell, 2003).

After the CAS standards survey questionnaires were returned, I analyzed their data using descriptive statistics. After the data was analyzed, a summary was prepared that identified emerging themes or trends within this data.

Survey Responses

Descriptive statistics quantitatively describe the main features of a collection of data and are usually used to describe or summarize data in a meaningful way such that patterns might emerge (McQuarre, 2006; Trochim, 2004). Descriptive statistics differ from inferential statistics in that they are not developed based on probability theory. Instead, as its name suggests, descriptive statistics are a simple way to describe data (Field, 2005). They do not allow any conclusions to be drawn beyond the analyzed data (Field, 2005; Trochim, 2004). In this study, the mean averages of the two population's responses were used to describe the numeric data collected by this survey. 
I calculated the mean averages from this survey data to descriptively illustrate the central tendencies of the participants. The mean average is the most popular and wellknown measure of central tendency (Creswell, 2006). The mean is determined by finding the sum of all the values in the data set and dividing that number by the number of values in the data set (Trochim, 2004).

\section{Focus Group Data Analysis}

I analyzed focus group data for common themes. I read each transcript and identified the frequencies of particular ideas and the sources of these ideas. I then identified the recurring themes that are common to these groups of reoccurring ideas, and any related themes were clustered or merged (Carey \& Smith, 1994). To cluster and sort the topics and the themes, I used the scissor and sort technique. This is a simple and an effective method for analyzing a transcript of a focus group discussion (Stewart, et al., 2007).

First, I read the transcripts and identified relevant sections. Based on this initial reading, I identified major topics, and then I coded transcripts according to each topic. I followed the following steps to analyze the focus group data:

1. I read the focus group transcripts and identified the portions of the transcripts that are relevant to the problem that is being explored by this study. After this initial reading, a classification system was developed based on the identifiable topics or themes that reflect the CAS Standards that emerged from these transcripts. For this study, the steps followed to classify themes and determine topic areas (Krueger, 1994) are:

- List key words and phrases until all important ideas are identified. 
- Note recurring ideas but do not repeat ideas, then determine the shared theme of these ideas.

- Identify and group any similar themes. These groups of themes become the list of discussed topics.

2. Next, I coded relevant portions of text to reflect their relationships with one or more of the identified themes. The coded material ranged from phrases and single sentences to longer dialogues between participants. The only requirement that qualified material for coding is relevance to the particular category with which it is identified. This coding exercise required repeated passes through the transcript to allow categories of topics to evolve as I gained insights into the content of the group discussion. The amount of material coded for any one topic depended on the importance the participants demonstrated for a topic through the amount of the discussion they devoted to it.

3. After completing this coding process, the individual pieces of coded material were sorted and aligned according to relevance. This yielded a set of sorted materials that became the basis for a summary report.

4. A colleague who was a professional staff member at Missouri S\&T in the early 2000's reviewed the subsets of survey data and focus group transcripts. This individual's analysis of these data was consistent with my interpretation, thereby enhancing the credibility of these findings.

After analyzing the written transcripts, the observed non-verbal activities were matched to align with their corresponding question responses (e.g., enthusiasm, agreement, indifference or disagreement). Matching these data sets helped to better understand participant sentiments toward specific responses (e.g. 
participants acknowledging their agreement by nodding their heads or the enthusiasm suggested by an individual as they made a statement). This information contributed to understanding various comments' purpose for being stated and their reception by the group.

Quality Assurance and Ethical Considerations

\section{Survey Instrument Quality Assurance}

To help ensure the reliability of the survey instrument used in this study I derived the questions from the CAS Self-Assessment Guide. This study's adaptation of the CAS Self-Assessment Guide was modeled after similar research applications applied at other universities (Dorman, 2012).

The CAS Self-Assessment Guide. The CAS self-assessment guide was developed to translate the sets of CAS standards into formats that enable self-assessment (Stayhorn, 2006; White, 2006). Several university student affairs units have similarly adapted the CAS Self-Assessment Guides to assess various programs or departments and used the findings to guide the implementation of their own improvement plans (e.g. Dorman, 2012; Cooper \& Saunders, 2000). Major professional student affairs organizations (the American College Personnel Association, the Association of College and University Housing Officers -International, and the National Association of Student Personnel Administrators) as well as many senior student affairs officers also recognize the effectiveness and reliability of adapting the Guide as a means of incorporating the CAS Standards into a program review. (Bresciani, 2006; Dorman, 2012; Paterson \& Carpenter, 1989), Also, Cooper and Saunders (2000) revealed that student affairs practitioners considered the use of this self-assessment guide to be beneficial with regards to identifying program and organization shortcomings. 
Triangulation. The dependability of the survey instrument and of the qualitative findings is also being ensured by the use of methodological triangulation. The reason for using triangulation as a form of research in this exploratory study is to enhance confidence in the ensuing findings (Hammersley, 2008). Triangulation's value as a research practice has been repeatedly recognized as and endorsed for use in formative studies (Bullock \& Ory, 2000; Fraenkel \& Wallen, 2003). Triangulation improves a study's credibility through the use of different research methods (Bryman, 2002). Methodological triangulation involves using separate, but coinciding, collections and analyses of qualitative and quantitative data. The two resulting data sets are usually either interpreted together or are integrated during their analysis (Creswell, 2003). Applying triangulation methods in this way with the use of a new survey-based measure, such as the survey instrument used in this study, can improve the confidence in the validity of instrument's information if its findings can be confirmed with another method, such as the observations collected from focus group discussions (Bryman, 2002).

\section{Considerations}

There are four considerations that I was cognizant of while conducting this study. These considerations were the trustworthiness of focus group data, how bias could influence the investigator, researcher objectivity, and dependability concerns with triangulation.

Focus group trustworthiness. Focus group data quality depends on a number of factors; the number of participants, the appropriateness of sample populations, the relevance of questions, the moderator's abilities, and effective data analysis (Krueger, 1993; Morgan, 1993). To help ensure the trustworthiness of the data from this study's focus groups, the design of their format, the selection of participants, and analytic 
techniques were modeled after focus group instruments used in similar fraternal organization studies (e.g., Brown, 2007; Callais, 2011; Morgan, 1993; Tyler, 1980).

Evaluator bias. A significant factor considered in the construct of this program evaluation as well as in the evaluation's results is the potential for evaluator bias (Cresswell, 1998). As an administrator of the University's Student Affairs Division I am either directly or indirectly involved in the supervision of the division's programs and services. One of my specific duties is direct supervision of the Director of Student Life, who provides direct oversight and supervision for the Fraternity and Sorority Life Office. As such, I have a particular interest in seeing favorable outcomes result from the division's programs and services, including those in the Fraternity and Sorority Life Office.

While my bias was a potential influencing factor in this evaluation, my supervisory responsibilities did not necessarily create a great enough conflict as to compromise this evaluation. Similar studies have been successfully conducted by persons with similar relationships with the program being evaluated (e.g. Brown, 1997; Callais, 2002; Cory, 2011; Scroggs, 1994). In these other studies, researchers noted that their involvement in the review aided them by providing previously unknown insights the program and its activities.

To minimize participant concerns with potential researcher bias, I incorporated into the participant recruitment an explanation of the study's purpose as well as the nature of their involvement in the study (Appendix F). In this explanation, I communicated my relationship to the Fraternity and Sorority Life Office and that this survey will not be used to evaluate the performance of any staff member or the outcomes of any program or service. I also clearly communicated both verbally and in writing their rights while 
participating in research, that their participation is voluntary, and that all data collected will be kept strictly confidential.

I also provided study participants with copies of a memo from my supervising Vice Chancellor indicating that none of the information revealed in this study would be used to evaluate the performance of any staff member or program activity that reported to me. This memo also informed participants that no information resulting from this study could be used to affect any participants' standing or relationship with Missouri S\&T (Appendix E).

Researcher objectivity. Some note that a significant disadvantage associated with any internal reviews is a potential for bias since those conducting the review have a vested interest in the program being reviewed (Gregory, 2003; Miller, 2003). Use of the CAS Standards offsets potential internal design biases. Each edition of the CAS Professional Standards in Higher Education contains a detailed account of the history of CAS along with an explanation of the CAS approach to self-regulation and selfassessment.

Likewise, the CAS Self-Assessment Guides provide step-by-step directions on how the process works. CAS also maintains a list of programs nationwide that have engaged in the self-assessment process (Koepsell, 2008; Miller, 2003). My research advisor also served as a peer reviewer who also checked for potential biases in this study's design. Committing to utilizing these external resources offsets concerns with researcher bias in other internal review studies (Koepsell, 2008) and for the same purposes, this was done in this study.

Since I do have a vested interest in this study, my subjectivity cannot be completely eliminated. However, I do possess a significant amount of relevant 
professional experience and as a supervisor, my perspectives are an influence on the Fraternity and Sorority Life Office. So including my subjective perspective can also benefit the qualitative portion of this study.

Triangulation concerns. A concern with using triangulation is the potential that multiple sets of findings may be inconsistent. However, as Webb et al. (1966) observed, this also underscores the limitation of relying on just one measure or method and then being unaware of a potential inconsistency. Inconsistencies may suggest many things such as the need for alterations being needed in the inquiry methods being applied (Morgan, 1993), that the primary research method in this study the survey is not rigorous enough to sustain the study (Thurmond, 2001), or that the study's other method's design was such that they did not actually contribute to the research (Thurmond).

Another concern with triangulation is that even if the exercise shows that discrete findings converge, it does not demonstrate their accuracy because their similarity could be a result of each finding being similarly flawed. Despite this possibility, the researcher is wise to accept converging findings as evidence that the findings may be accurate and that diverging findings are evidence that at least one finding is flawed (Bryman, 2002).

I gave consideration to this study's methods for collecting and analyzing data. This is a formative study intended to discover information. It was designed with the realization that significant unknowns potentially exist that cannot be presupposed but could influence the study's application and its findings. Therefore, any potential inconsistencies have been noted in the study's summary (Bryman, 2002) and serve as information to be used to help judge the utility of this evaluation (Patton, 1997). 


\section{Conclusion}

This program review used a case study approach to investigate client perceptions of the Fraternity and Sorority Life Office. The CAS Standards for Fraternity and Sorority Advising served as a pre-existing set of accepted performance standards that provided a framework for studying program performance. A survey instrument and focus group discussion guidelines were both prepared by incorporating the program review elements of the CAS self-study guide.

The data that was analyzed includes descriptive statistics from the survey's returns and the themes that emerge from the survey, short-answer responses, and the focus group discussion transcripts. 
Appendix C

\section{LITERATURE REVIEW}

This literature review provides a perspective on the evolution of Greek societies, of Missouri S\&T and its Greek community, and the influences that have contributed to the evolution of the Missouri S\&T Fraternity and Sorority Life Office. This review also addresses the CAS Standards' merits as a standard for determining clients' expectations and it discusses the value of including the input of chapter leaders in this study.

\section{History and Context of Greek Societies}

An effective program evaluation provides an understanding of why the program is believed to be necessary and what needs to be addressed (Hogan, 2007). This why and what are both intrinsic to an organization's values and should be articulated in its mission and goal statements (Morgan, 1997). Thus, a program evaluation is better able to contribute to an organization's goals setting efforts when the researcher is familiar with the nature of the entity being studied. In this study, that entity is the Missouri S\&T Greek community. Understanding today's fraternities and sororities is a complex endeavor that requires a brief overview of the history, context, purpose, and espoused values of fraternal organizations (Jelke, 2001). Such an overview of Greek societies in higher education, and of Missouri S\&T's institutional and fraternal organization history, along with a review of contemporary issues associated with fraternities and sororities is a common background to include in a study of campus Greek Life programs (Jelke \& Kuh, 2003).

The Early Years

Phi Beta Kappa, founded in 1776, is generally considered to be the first collegiate Greek-letter organization. It was established in response to the students' interests and 
desires that were not being met in the classroom or other university controlled venues (Whipple \& Sullivan, 1998). Phi Beta Kappa's founding was based on the principles of social interaction, free discussion, and the open advancement of learning. This society had the mystery of secrecy, rituals, oaths of fidelity, a handshake, a motto, and a badge for external display. This society also espoused high ideals, a strong tie of friendship and camaraderie, and intended to share its values through expansion to other colleges (Owen, 1991). These characteristics are some of the same as those present day fraternities and sororities (Brown, 2007; Jelke, 2001; Kalkowski, 2005).

The environment on American college campuses in the late $18^{\text {th }}$ century did not lend itself to the founding of other groups like Phi Beta Kappa. The universities of that time generally adhered to curricula and governing structures placed significant restrictions on students' intellectual and personal freedom (Whipple \& Sullivan, 1998). While the students of this era did form groups such as literary clubs and debating societies, the institutional constraints of the era limited other student activities effectively enough that nearly 50 years passed between the founding of Phi Beta Kappa and the establishment the next successful Greek-letter fraternal society (Brubacher \& Willis, 1997).

By the 1820s, the curricula and academic missions of some American universities were shifting away from religion to include a variety of subject areas, including literature and the natural sciences (Owen, 1991). In the midst of such a curricular transition at Union College, the first three contemporary social fraternities came into existence. The first of these Greek-letter societies was the Kappa Alpha Society, founded in 1825. It was followed by the founding of Sigma Phi and Delta Phi in 1827 (Aston \& Marchesani, 1991). These three Union College fraternities are often referred to as the "Union Triad." 
Their bylaws set them apart from Phi Beta Kappa as well as other student societies in that they considered their purpose primarily to be expanding their members "social" skills and learning about topics that were not part of their formal curricula, such as poetry and politics (Brubacher \& Willis, 1997).

Often using the Union Triad fraternities as models, other social fraternities emerged on college campuses in the United States - first in the Northeast, then in the Midwest, and later in the South. These fraternities gained rapid acceptance (Brubacher \& Willis, 1997; Owen, 1991). This shift was so dramatic that within 20 years after the founding of the Union Triad fraternities, on many Northeastern and Midwestern campuses, fraternities effectively replaced student literary societies as students' primary means of campus participation (Brown, 1920). School officials frequently considered these early fraternities to be potential threats to the cultural fiber of their associated college campuses. These concerns brought societies regular scrutiny and they were often forbidden to meet outside the classroom. To counter this scrutiny, fraternal organizations adopted secret practices like those of Phi Beta Kappa by collecting and developing artifacts, stories, semiotics, and rituals (Callais, 2002; Johnson, 1972).

\section{The Evolution of Modern Greek Societies}

Post-Civil Warfraternities. After the Civil War, interest arose at many southern campuses in preserving elements of their region's pre-war cultural heritage. This interest contributed to the impetus for founding fraternities that, in addition to offering member opportunities like those of existing fraternities, embraced the social hierarchy and the cultural values that were propagated in the pre-civil war South (Owen, 1991). The first post war, southern fraternities were named: Kappa Sigma, Sigma Nu, Kappa Alpha, Sigma Phi Epsilon, Alpha Tau Omega, and Pi Kappa Alpha. These five societies were all 
founded in the late 1860s and came to be known as the "Virginia Circle" fraternities (Aston \& Marchesani, 1991).

Sororities. The first documented admission of women to an institution of higher learning in the United States occurred in 1837, when Oberlin College admitted women students (Callais, 2002; Turk, 2004). Fourteen years later, the first social sorority, the Adelphean Society (renamed Alpha Delta Pi in 1905), was founded at Wesleyan College in 1851. In 1852, its founding was followed at Wesleyan College by the Philamathian Society (eventually renamed the Phi Mu Women's Fraternity). In much the same way that the Union Triad became the models for forming other fraternities, these two women's secret societies became the designs that were followed to form sororities (Callais, 2002).

The few colleges that admitted women prior to the Civil War usually served as finishing schools with curricula consisting largely of English literature, composition, drama, French, art, and music (Turk, 2004). During the Civil War and the years that immediately followed, women's enrollment patterns changed dramatically (Johnson, 1972). The military's wartime demands for recruits contributed to a decline in the number of men attending college. The war's logistical needs increased the demand for persons with professional training in fields such as medicine, engineering and law, and women helped meet those demands (Chamberlain, 1991). The growing number of women college students also corresponded with an increase in the number of women interested in joining social societies (Johnson, 1972).

The post-Civil War growth in the female college population had an effect on sorority membership in much the same way that fraternity interest grew in relation to the early $19^{\text {th }}$ century growth in the male student population (Turk, 2004). New sororities 
appeared beginning with the founding of Kappa Alpha Theta and Kappa Kappa Gamma in 1870 at Monmouth College. These two societies established a pattern that eventually came to prevail; college women did not want to belong to the same societies as did men, and they did not want to be secondary to male students (Johnson, 1972; Turk, 2004).

Having their own, completely separate, societies provided women with selfgoverned social privileges that were independent of their colleges and the social fraternities (Johnson, 1972; Turk, 2004). The continued development of sororities through the later part of the 1800s allowed women an opportunity to share their common experiences and provided them their own alternative to the demands of their academic work (Hunt \& Rentz, 1994).

Greek Societies Enter the $20^{\text {th }}$ Century

Sororities and fraternities had become an established part of many campus communities by the start of the $20^{\text {th }}$ Century. These groups were social alternatives for college students that provided them with an outlet from the rigors of their academic requirements (Anson \& Marchesani, 1991). In spite of, or more likely because of, their growing popularity, many school officials at that time continued holding to the disposition that these societies emboldened students' resistances to the degrees of discipline and control being imposed at that time by the colleges (Komives \& Woodard, 2003).

By the end of the $19^{\text {th }}$ century, expansions of land-grant campuses were providing more post-secondary education options for students and were contributing to an increased interest in higher education; these trends prompted similar campus growth at private schools. At this same time, although several university leaders questioned the merits of fraternal organizations, they continued to appeal to a large number of students (Gregory, 
2003). With many college communities either unprepared or unwilling to accommodate this influx of students, these conditions resulted in situations where college administrators found it advantageous to be more amenable to fraternities and sororities, often on the condition they provide housing for students (Anson \& Marchesani, 1991; Kuh et el.,1989).

\section{Post World War II Greek Societies}

A surge in college student enrollment even greater than the one experienced in the late $19^{\text {th }}$ Century occurred immediately after World War II (Blimling, 1993). The benefits provided military veterans by the G.I. Bill made attending college affordable veterans (Brubacher \& Willis, 1997). The extraordinary number of veterans who opted to take advantage of these benefits created a student housing shortage issue similar to the one seen in the 1890s. Also, much like the 1890s, fraternity and sorority houses again became part of the solution to address housing shortages (Anson \& Marchesani, 1991). The popularity of Greek societies persisted for 20 years following World War II. Greek chapters offered students reasonable accommodations in communal environments that were selective in their membership and allowed activities not permitted in university controlled housing (Christensen \& Ridley, 1983).

Greek Society Evolution; 1970 to Today

Students' interest in fraternities and sororities experienced a decline through the 1960s. The movement away from in loco parentis that began during that time was detrimental to fraternal organizations, as university rules governing student behavior were gradually relaxed, and student self-governance became more commonplace (Komives \& Woodard, 2003). Several societal changes such as many states lowering drinking ages from 21 to 18 , the Civil Rights and anti-Vietnam war movements, and 
lowering the voting age to 18 fostered an unparalleled sense of freedom among college students (Gregory, 2003). At the same time, interest in joining fraternal organizations waned dramatically as the interests of college students of the time focused less on institutionalized organizations (Kalkowski, 2005).

By the mid-1980s, a different set of societal factors, such as states raising their drinking ages back to 21 , and renewed student interest in belonging to social organizations influenced college student culture (Callais, 2002; Kalkowski, 2005). At this same time, there was also a resurgence in the interest in fraternal organizations among college students (Anson \& Marchesani, 1991) which resulted in a sizeable increase in fraternity and sorority membership.

This membership growth taxed both chapters' and national fraternal organizations' available resources that had been diminishing because of the reduced member contributions during the previous decades (Whipple \& Sullivan, 1998). This limited amount of resources retarded both the fraternity and sorority chapters' ability to maintain service standards as well as the national organizations' ability oversee and support their chapters (Brown, 2007). This created an environment where fraternal organizations were more loosely affiliated with their chapters and many chapters were organizationally more autonomous than they had been at any time in their history (Kalkowski, 2005).

During this same time, a two-decade long trend of relaxing university policies governing student behavior diminished institutions' abilities to control the routine activities of student organizations (Kalkowski, 2005). The combined factors of reductions in universities' ability to exercise control over chapter activities, diminished chapter resources, and national fraternal offices' limited abilities to be involved with chapters 
resulted in campus fraternal organizations adopting practices and activities that had little resemblance to those of their predecessors particularly regarding their facility management, alcohol use, and social activities (Brown, 2007; Cory, 2011; Jelke 2001; Kalkowski, 2005).

Since 1980, fraternal organizations have, with increased frequency, had to cope with undesirable perceptions held by persons who are neither affiliated with any Greek organizations nor are they usually affiliated with a university community (Callais, 2002). Largely due to their secret nature, it has been difficult for unaffiliated persons to understand what constitutes a fraternal organization (Callais, 2002; Drout \& Corsoro, 2003; Whipple \& Sullivan, 1998). Moreover, their evolution during the latter part of the $20^{\text {th }}$ century added to others' lack of understanding (Bureau, 2007; Gregory, 2003). While the original reasons for their establishment, to afford students co-curricular and social venues, have remained prominent, by 1980, many outsiders are unclear whether today's fraternity and sorority chapters still espouse their founding principles (Asel, et al., 2009).

Media attention on fraternal organizations has also contributed to negative perceptions of fraternal organizations by focusing on issues such as excessive use of alcohol and other controlled substances, hazing, and poor facility management (Jelke, 2001). This exposure has portrayed Greek societies as organizations with values that have little resemblance to those of their predecessors and disconnected them from the purposes of their host institutions (Callais, 2002; Drout \& Corsoro, 2003).

Another challenge faced by fraternal organizations comes from legislation that either directly or indirectly targets some of their social practices (Bureau, 2007; Callais, 2002; Jelke 2001). In the early 1980s various state and local laws raised drinking ages to standard age of 21 years old. At this same time, other laws were passed that restricted 
practices such as hazing and established responsibility standards for hosts of social events involving alcohol (Jelke \& Kuh, 2003; Peterson \& Carpenter, 1989).

A collateral issue resulting from this legislation has been an increased expectation that fraternity and sorority chapters develop their own social guidelines and responsible alcohol use programs (Brubacher \& Willis, 1997; Gregory, 2003). The impetus that promoted the development of these policies has primarily come from the groups providing chapters with liability insurance (Dugan, 2008). The additional potential for liability litigation resulting from this legislation caused insuring agencies to expect their insured Greek organizations to enact effective risk management practices as a condition of their continued coverage (Drout \& Corsoro, 2003).

Current traditional aged students, often referred to as millennial students, along with their parents, also expect Greek organizations to comply with regulations (Drout \& Corsoro, 2003). Today's students often embrace a consumer perspective when considering joining a fraternity or a sorority (Cory, 2011, Gregory, 2003). These students (and parents) are expecting the fraternity or sorority experience to favorably impact their academic success and development (Callais, 2002; Kalkowski, 2005). These external and consumer based expectations have and continue to change the nature of the relationships among chapters, their host institutions, and their national headquarters (Gregory, 2003).

However, in spite of how Greek chapters have evolved, the various fraternal organizations' governing bylaws have remarkably consistent values statements (Drout \& Corsoro, 2003). Most organizations' bylaws hold many, if not all, of following founding principles:

1) To complement the academic mission of the college;

2) To develop leadership among its members; 
3) To serve the community;

4) To develop character;

5) To develop the whole person;

6) To build community;

7) To develop lifelong friendships (Gregory, 2003).

Whether Greek organizations adhere to the principles they prescribe is subject to debate.

Along with perceptions of some external audiences, researchers have found Greek members' behavior to be problematic (Dorman, 2012; Jelke \& Kuh, 2003). Many studies' findings suggest that fraternity or sorority affiliation contributes negatively to student development through behaviors such as alcohol abuse (Eberhart, Rice, \& Smith, 2003), academic dishonesty (McCabe \& Bowers, 1996), sexual promiscuity (Eberhart et al., 2003), and hazing (Drout \& Corsoro, 2003). However, there is also research that suggests fraternities and sororities contribute positively to spiritual development (Kuh \& Gonyea, 2006), involvement with peers and groups (Astin, 1992; Pascarella \& Terenzini, 2005), leadership development, and retention (Astin, 1992; Tinto, 1993).

In spite of their demonstrated abilities to contribute to student development, Greek organizations are sometimes perceived to be a double-edged sword. On one side, they have demonstrated through their history an ability to provide for students lifestyle needs and can be an effective means for fostering campus involvement (Asel, Seifert \& Pascarella, 2009; Callais, 2002; Maisel, 1990). On the other side, campus Greek chapters have been targeted as focal points for encouraging student misconduct and fostering campus militancy (Kuh, Pascarella \& Wechsler, 1996). As such, Greek organizations tend to elicit strong emotional reactions, both positive and negative. Their positive supporters tend to focus on the services provided to the members and the community 
services performed (Maisel, 1990). Those with negative impressions tend to see Greek organizations as shallow, elitist, and unworthy of scholarly attention (Turk, 2004).

These varied perspectives about Greek organizations, their intended practices, and observed behaviors often make it difficult for school officials, non-Greek students, faculty or staff, as well as the public, to see the merits of or the purposes served by hosting college Greek chapters (Jelke, 2001). This inability to perceive any merits that result from member affiliation with Greek chapters or that result from chapter relationships with universities has been the contemporary rationale for conducting studies regarding the common needs, and relationships and expectations of and from Greek chapters (Bureau. 2007; Cory, 2011; Jelke \& Kuh, 2003).

\section{Missouri S\&T and its Greek Organizations}

Since its inception, the Missouri S\&T Greek community has been influenced by the same factors that contributed to the founding and development of other campus Greek societies in American higher education. In addition to the influences from outside Missouri S\&T, over the course of its existence specific campus factors have also shaped the evolution of this University's Greek chapters. Understanding how the Missouri S\&T Greek community has evolved to become what it is today is important to better understand the need for this exploratory study (Bolman, \& Deal, 2003; Bureau. 2007). The Founding of the Missouri School of Mines

Missouri S\&T was founded in 1871 in what was then a small, remote mining and railroad community - Rolla, Missouri. At that time, other than its location in Missouri's lead mining belt, there was little about the city's characteristics that lent to it being suited to host of a technological university (Roberts, 1946). With the arrival of the first Missouri School of Mines students came an immediate need to provide them with lodging, meals, 
and social venues. Initially, these students could be accommodated in the homes of local residents and the school's faculty (Christensen, \& Ridley, 1983) but by the end of the $19^{\text {th }}$ century, the Missouri School of Mines experienced a dramatic growth in its enrollment (Roberts, 1946).

This student enrollment growth can largely be attributed to efforts the school's director at that time, George Edgar Ladd. Dr. Ladd arrived at the Missouri School of Mines in 1897 and immediately set out on an ambitious agenda to expand both the size and the reputation of the school (Christensen, \& Ridley, 1983). As a part of his effort to recruit and retain students, Dr. Ladd embraced non-curricular activities such as athletics, music, drama, and social fraternities (Roberts, 1946). His efforts resulted in substantial increases in support given by the State of Missouri; and within five years, the campus enrollment more than doubled (Viles, 1939).

By 1900, the school's student population exceeded 250 and had become larger than what the Rolla community could accommodate in their homes and boarding houses (Viles, 1939). In addition, while once welcomed at community social functions, the numbers of students now attending such events sometimes outnumbered the local residents. Feeling like a minority within their own community, Rolla's residents became less inclined to include the college students at their local activities (Christensen, \& Ridley, 1983). It was at this time when some Missouri School of Mines students began investigating other potential lodging opportunities.

Through their inquiries, campus administrators became aware that two social fraternities were willing to assist the school by leasing boarding houses if the students could form chapters and allow these fraternities to come to Rolla (Lloyd, 2005). The local 
shortages of lodging and social venues made Greek societies attractive to Rolla students, much like what was happening on campuses nationwide (Brubaker \& Willis, 1997).

\section{The Missouri S\&T Greek Community}

By 1903, there was sufficient interest in having fraternity chapters at the Missouri School of Mines within both the student population and the campus administration to support to the colonization of the Sigma $\mathrm{Nu}$ and the Kappa Alpha fraternity chapters (Roberts, 1946). These two fraternity chapters experienced immediate and strong student participation and, in their first year, 19 students were activated as chapter members. The following year, the Kappa Alpha Chapter leased its first house and the Sigma Nu Chapter made arrangements for its active members to live and meet at a boarding house (Lloyd, 2005). Student participation in other extra-curricular activities such as athletics, music, and drama also grew and was encouraged by Dr. Ladd and his immediate successors (Roberts, 1946).

During the next 30 years, six more fraternity chapters were founded at the Missouri School of Mines. In 1931, the school recognized an Inter-fraternity Council as a student organization (Ridley \& Christenson, 1983). From the founding of its first fraternity chapters in 1903 through the early 1930s, the Greek community also received considerable attention and direction from the school's senior administrators (Roberts, 1946; Viles, 1939). During that time, the fraternities were integral to the campus fabric.

Over half of the student population was made up of active members of Greek chapters and the chapter houses were the most common form of housing for students (Roberts, 1946).

Subsequent to this period, there was a 4-decade period of decline in the University's support for the Greek chapters. This decline was due to several factors, but 
the most significant were economic (Christensen \& Ridley, 1983). During the economic depression in the 1930s, the School of Mines incurred considerable reductions in its state support and experienced a drop in enrollment. These factors limited the school's ability to provide support to co-curricular activities, including fraternities (Roberts, 1946).

The 1930s enrollment decline also resulted in a reduction in the number of students who joined the Greek chapters. The loss of active member contributions further reduced chapters' resources to a point where some were on the verge of insolvency (Roberts, 1946). Spurred by a combination of concern for students and loyalties from past chapter memberships, several faculty members, with the support of some chapter alumni, assumed active roles with chapters including advising, and providing their own financial support (Lloyd, 2005; Viles, 1939).

The faculty and alumni activism in the Greek chapters that began during the depression continued to be a significant part of the campus culture through the late 1940s. It then gradually declined to the point where, by the late 1960s, active faculty involvement became a sporadic occurrence (Christenson \& Ridley, 1983). However, elements of a culture of faculty and alumni activism is still evident in most chapters' artifacts and faculty members still actively participate in a handful of chapters (Lloyd, 2005). This precedent of faculty involvement, while largely historic, still influences the Missouri S\&T Greek culture. It laid the groundwork for a perception within the Greek community that chapters cannot rely on the University administration for support. Reliable support came from alumni and some individual faculty members (Norman, 2009).

While the formal duty to oversee the Greek chapters always rested with the institution's dean, the economic circumstances of the 1930s put much more power into 
the hands of the alumni and faculty (Christenson \& Ridley, 1983). From roughly 1940 to 1990, each administrative change in the University was seemingly accompanied by diminished campus support for its Greek chapters (Christensen \& Ridley, 1983; Lloyd, 2005).

Post War Greek life at Missouri S\&T. During the 15 years following World War II, campus enrollment steadily grew from roughly 700 students in 1945 to an undergraduate enrollment of nearly 3,000 students in 1960. The enrollment growth resulted in faculty members teaching more credit hours and advising more students (Christensen \& Ridley, 1983). These additional academic demands contributed to a general decline in faculty involvement in campus extra-curricular activities of all sorts, including advising fraternities (Christensen \& Ridley, 1983; Lloyd, 2005).

Much like previous enrollment increases, this spurred comparable growth in Greek community membership. During this time, six more fraternity chapters were established, and average chapter size grew from roughly 25 to 50 members (Lloyd, 2005). Also during this period, largely through alumni support, most chapters either acquired new houses or performed significant improvements to existing structures (Christensen, \& Ridley, 1983).

The establishment of sororities at Missouri S\&T. In 1945, less than 50 women were enrolled at Missouri S\&T, and they represented about 3\% of the student population (Ridley \& Christensen, 1983). By the early 1960 s nearly $15 \%$ of the enrolled students were women. While still a relatively small portion of the total enrollment, with numbers exceeding 500, the campus female population became a viable enough to support femalespecific activities and organizations, including some sonorities (Ridley \& Christensen, 1983). 
The first sorority was founded on the Missouri S\&T campus (then named the University of Missouri - Rolla) in 1969. The Lambda Sigma Sorority was founded that spring with five original members. Lambda Sigma originated as the little sisters of the Sigma Pi fraternity and the University of Missouri - Rolla chapter kept that affiliation for 3 years. In 1972, it petitioned to become a chapter of the Kappa Delta Sorority. Their membership was approved in the spring of that year, making it the University's first national sorority chapter. The two other active Missouri S\&T sororities also established chapters during the 1970s, Zeta Tau Alpha in 1973 and Chi Omega in 1979 (Lloyd, 2005).

The contemporary Missouri S\&T Greek community. The Missouri S\&T Greek community has grown to include 24 fraternity and sorority chapters (Lloyd, 2005) and has an active membership that represents nearly $25 \%$ of Missouri S\&T undergraduate students (Brubacher, \& Willis, 1997; Lloyd, 2005). The fundamental characteristics of today’s Missouri S\&T Greek communities are similar in their composition and organizational structure to Greek communities on most other college campuses (Christensen, \& Ridley, 1983; Norman, 2009). Additionally, like chapters at other campuses, Missouri S\&T chapter involvement constitutes a significant portion of their members' routine activities (Norman, 2009). The Fraternity and Sorority Life Office within the University's Student Activities Department and located in the Havener Center provides chapters with administrative and advising support. This structure is similar to those on other campuses (Norman, 2009).

The Missouri S\&T Fraternity and Sorority Life Office was founded in 1990 with no campus precedent to follow in its design. Up to that time, there was no dedicated centralized source of University support and supervision of its fraternities and sororities. 
Because the long accepted culture of support for the Greek chapters from faculty advisors or alumni, advising quality prior to 1990 varied according to individuals' competencies and commitment (Norman, 2009).

The shift from the University's lack of involvement in its Greek community during this 50-year period coincided with the appointment of its first dean of students in 1977 (Christensen \& Ridley, 1983). When the dean of students position was established, Missouri S\&T was coping with the same challenges facing many campuses due to a decade-long period of dramatic change in polices and social expectations governing the school/student relationship (Astin 1992; Boyer, 1987; Kuh, 1991). Enforcement of University polices was now more complex. Issues such as having to enforce conduct codes while providing students due process protection, initiating a process for relief for students when discriminated against, or protecting the privacy rights of students were relatively new in higher education in the 1970s. The remedy for many schools, including Missouri S\&T, was to establish an office to manage these issues (Komives \& Woodard, 2003).

At Missouri S\&T, this new dean of students was assigned formal responsibility to oversee the University's policies governing student behavior and student rights. Also assigned to this new office was responsibility for overseeing the activities of the University's Greek chapters (Christensen, \& Ridley, 1983). While it is not uncommon for a dean of students to oversee Greek Life (Norman, 2009), in this instance, unlike most deans of students, there was no intention that the Missouri S\&T dean would do more than ensure student compliance with the University's code of conduct. This dean position was established to be a policy adjudicator, and as such, was perceived by the Greek community to be a potential adversary rather than as an ally (Christensen, \& Ridley, 
1983; Norman, 2009). In effect, adding a dean of students office primarily resulted in further distancing the University from its Greek community (Christensen \& Ridley, 1983).

This new period of benign University involvement created a culture where the University's formal role with the Greek community was to enforce policy compliance. The Greek response to this change was to disclose as little activity information as possible to the University, because information provided only helped to enable the University to identify infractions (Norman, 2009).

Office of Fraternity and Sorority Life

When the Fraternity and Sorority Life Office was created in 1990, the longstanding deficiencies in the oversight and support provided to the University's Greek chapters were only secondary reasons being used to justify the need for this Office. The primary reason to establish this Office was to improve the University's ability to respond to a growing demand for timely and accurate information about the Greek community from external constituents (e.g., national fraternity \& sorority offices, Greek alumni groups, and house corporations) (Christensen, \& Ridley, 1983). These groups wanted a dedicated and reliable campus unit that could be used to gather information such as grade point averages, volunteer services, campus involvement, and chapter rosters (Lloyd, 2005).

Since its establishment, the Fraternity and Sorority Life Office has been serving as an information-gathering service and has provided support for several administrative needs in the Missouri S\&T Greek community. It also provides some program support but has done so on a sporadic basis that follows no observable plan or any stated intentions (Norman, 2009). 


\section{Accreditation Review}

As a part of the preparation for a 2009 University accreditation visit, the Missouri S\&T Fraternity and Sorority Life Office prepared a summary report of its services to the campus Greek chapters. The review summary noted that this Office was not able to provide evidence that demonstrates how it contributes to University's strategic goals or meets the institutional mission (Missouri S\&T, Office of the Chancellor, 2010). The findings of the internal review were not surprising.

Many contemporary campus Greek programs are scrutinized and questioned as to whether their services or programs are still viable or are out of step with client demands (Bureau, 2011; Jelke, 2001). This 2009 Missouri S\&T accreditation visit observation regarding the Missouri S\&T Fraternity and Sorority Life Office has been the precipitating incident that spurred campus interest initiating a similar review that could scrutinize the merits of this Office's programs (Norman, 2009).

\section{CAS Standards}

In 1983, the Council for the Advancement of Standards in Higher Education (CAS) completed a set of general standards to provide benchmarks regarding professional practices for student affairs professionals (Creamer \& Mable, 2002; Dorman, 2012). Today, 43 different sets of these standards are in use and each set serves as measures for evaluation, staff development, and program planning for a different form of student service or support (White, 2006, Dorman, 2012). The CAS standards are now widely considered to be a valuable resource for student support and services practitioners (Fraenkel \& Wallen, 2003).

Founded in 1979, the Council for the Advancement of Standards in Higher Education is a consortium of over 35 professional associations. The goal of CAS has 
been to establish and promote the application of a series of standards and guidelines to various functional areas within higher-education. CAS endeavors to see that, when applied, its standards will foster student learning and development, quality assurance, and professional integrity (White, 2006).

Among this consortium of organizations, three nationally recognized student affairs professional associations (the American College Personnel Association, the National Association of Student Personnel Administrators, and the American College and University Housing Officers - International) played the leading roles in establishing the standards (Dorman, 2012; Miller, 2003). This early and continuing involvement by these professional organizations has had a significant influence on the CAS Standards becoming well known, highly regarded, and nationally recognized assessment benchmarks for student affairs and student support services (White, 2006).

Since their introduction in the early 1980s, the use of the CAS standards has steadily increased. Annual reports of CAS activities show impressive levels of use by a range of educational programs and services at colleges and universities throughout the United States and Canada (Dorman, 2012; Stayhorn, 2006). In addition to institutional acceptance, many professional association-related activities also regularly use CAS materials as performance benchmarks. Likewise, many master's degree programs have adopted the CAS Standards into their teaching of young professionals with the expectation that this will encourage them to use these standards and guidelines in their careers (Miller, 2003).

CAS Standards for Fraternity and Sorority Advising

One of the 43 sets of standards addresses fraternity and sorority advising (Dorman, 2012). For the purpose of applying these standards, CAS delineates college 
fraternal organizations as being campus social fraternity and sorority chapters whose primary activities are co-curricular or social in nature (Bureau, 2011; Dorman, 2012).

The CAS Standards for Fraternity and Sorority Advising as well as the other 42 sets of CAS Standards use the same 12 common criteria categories (CAS, 2012). Embedded within these general standards for fraternity and sorority advising are standards specific to the learning and development outcomes for high quality fraternity/sorority affairs programs (Bureau, 2007; Jelke, 2001) (Appendix B).

These CAS Standards expect student affairs professionals who advise fraternal organizations to support individual student development and work to advance organization and institutional goals (CAS, 2006). These standards consider the primary role of fraternity and sorority professionals to be assisting their stakeholders' efforts to position their Greek organizations to be able to actively contribute to the welfare and personal growth of their members (Mitstifer, 2012; Bureau, 2007). These standards also expect advisors to fulfill this role within the context of also helping their stake holder to construct their efforts in manners that allow them also to make positive contributions to their particular campus community environments (Bureau, 2007; Teamworks, 2011).

These fraternity and sorority specific standards stress the significant contributions that advisors' activities can make toward fostering scholastic excellence, leadership, civic engagement, friendship, and lifelong learning (Bureau, 2011) and are widely recognized as desired traits of a fraternal organization advisor (Jelke \& Kuh, 2003). Evidence of their general acceptance as performance standards comes from the endorsements of the two largest student affairs professional organizations. Both the American College Personnel Association and the National Association of Student Personnel Administrators have identified the CAS Standards for Fraternity and Sorority Advising as being the desired 
core competencies for persons who work with college fraternal organizations (Bureau, 2007; White, 2006).

While these CAS Standards were developed to be performance expectations for Fraternity and Sorority advisors, they have also been adapted by several universities (e.g., Lehigh University, University of Delaware, Northwestern University, Cornell University, and University of Rhode Island. Drexel University and Purdue University) to serve as performance review benchmarks for their Greek Life programs (Jelke \& Kuh, 2003; Koepsell, 2008). The schools that have used the CAS Standards for this purpose generally agree that they help effectively benchmark and assess program performance (Gregory, 2003). Using the Standards in this capacity has also been encouraged by the Association of Fraternity Advisors as well as the American College Personnel Association (Bureau, 2011).

\section{Greek Program Contribution Opportunities}

Pascarella and Terenzini (2005) have repeatedly asserted that both their and their colleagues' studies strongly indicate that campus culture affects college students' scholarship, influences students' social activities, and influences personal growth and development. Campus culture is a significant influencing factor on college student retention (Astin, 1992; Tinto, 1993). Campus environments where students feel they are members of the community and where they feel there is support to help them cope with their academic and personal challenges are the environments that tend to be found at schools with strong student retention rates (Pascarella \& Terenzini, 2005; Tinto, 1991). Student success scholars (e.g., Astin, 1992; Boyer, 1987; Kuh, 2001) assert that the significance of a campus environment's influence on student retention tends to be undervalued by university administrators (Astin, 1992; Kuh, 2001; Tinto, 1993). 
Therefore, college and university leaders who are interested in improving student retention are being encouraged to better understand how their campus environment outside the classroom can affect students and influence their retention (Asel et al, 2009).

Many of the co-curricular opportunities that contribute to this favorable out of class campus environment are most effectively made available to students through their involvement in fraternal organizations. Students, who are active members of fraternities or sororities, tend to become organization leaders and have more refined interpersonal skills (Kuh, 1991; 2001). Findings from various studies on college student success indicate that the co-curricular experiences associated with active involvement in fraternal organizations, foster student skill development and contribute to their academic success (Astin, 1992; Kuh, 2001; Pascarella \& Terenzini, 2005; Tinto, 1993). Growth in autonomy, self-esteem, and communication skills also results from increased personal development opportunities provided through active fraternal organization involvement (Astin, 1992). Also recognized is a relationship between students' time spend in volunteer positions and their likelihood to demonstrate leadership skill development (Cress et al., 2001; Sandeen, \& Barr, 2006; Yukl, 2002).

\section{Greek Chapter Leadership}

Greek chapter officers are generally considered to be leaders who are usually actively engaged with their organizations (Kelly, 2008). They are considered to be a group that can provide representative input about their organization's characteristics and its support needs (Cory, 2011; Jelke 2001; Jelke \& Kuh, 2003; Kelly, 2008).

Many of the best leadership opportunities for the members of fraternal organizations are obtained by becoming elected officers (Cory, 2011; Jelke, 2001). The bylaws governing most national fraternities and sororities have been written with the 
intent to empower elected chapter officers to be their chapters' leaders and these bylaws also expect these officers to embrace this leadership charge (Boschini \& Thompson, 1998; Dugan, 2008). In addition, traditions in most fraternal organizations that called for

officers to be elected by the active chapter members (Dugan, 2008). The combination of bylaw empowerment and member acclimation serve to further enable Greek officers to influence the culture and the values of their chapters (Asel et al., 2009; Norman, 2009). Studies involving Leadership in Fraternal Organizations

A review of their mission and purpose statements, web sites, and print materials can offer valuable insights into the value fraternal organizations place on leadership development (Cory, 2011). These documents portray leadership development as a hallmark of fraternal organizations (Bureau, 2007; Cory, 2011). They illustrate that many fraternities and sororities espouse leadership development as a primary outcome of membership. This is a contention frequently offered as a fraternal organization's most germane reason to allow it to be an active organization on a college campus (Dugan, 2008; Sandeen, \& Barr, 2006).

\section{Fraternal Organization Presidents}

While most Greek officers are considered to be active and engaged leaders, chapter presidents are considered to be a subgroup that is particularly able to provide information about their organizations (Jelke, 2001; Kelly, 2008). Greek chapter presidents commit more time to their position than do other officers (Kelly, 2008), feel more personally invested in their positions, and feel more significantly affected by their leadership experiences than are other Greek officers (Cory, 2011). Posner (2004) illustrates this point finding that fraternity presidents perceive themselves to be using leadership practices as more often than other chapter leaders. Kelly also noted a like 
difference between officer experiences and asserted that while there are many opportunities for college students to serve in co-curricular leadership roles, serving as fraternity chapter presidents can provide unique leadership benefits that are not available to other student leaders.

\section{Gender-Related Leadership and Perspective Differences}

Of the research about fraternal organization leadership, researchers usually found no significant differences in perceptions of leader effectiveness within fraternities versus sororities (Dugan, 2008; Posner, 2004). This lack of significant, gender-based differences is not consistent with research on gender differences in leadership development conducted outside of the fraternity and sorority context (Dugan, 2008; Eagly \& Johannesen-Schmidt, 2001). However, because of the limited research findings regarding fraternal organization leadership, it is possible that future studies about Greek leaders may reveal gender differences (Dugan, 2008; Mamarchev, Sina, \& Heida, 2003).

The findings of most other studies of gender differences and leadership styles show that there is a modest, but significant, difference between men's' and women's leadership styles (Eagly \& Johannesen-Schmidt, 2001). These studies' findings indicate that a woman's leadership style is more likely to involve mentoring and coaching, while a man's style is centered on command and control. As a result, women are considered to be more likely than men to be transformational leaders; leaders who help those they lead to develop their skills and talents, motivate them, and coach them to be more creative (Aburdene \& Naisbett, 1992). Therefore, researchers are encouraged to consider the possibility that gender may be a factor in how student leaders perceive Greek life (Dugan, 2008; Posner, 2004). 


\section{Conclusion}

A Greek presence has been on the Missouri S\&T campus since 1905. Based on the available information, the last attempt prior to this study to review its role or relationship with the school occurred nearly 80 years ago (Christensen, \& Ridley, 1983). Missouri S\&T's historical lack of institutional involvement with its Greek community left no precedent to follow, no explicit culture that supports campus engagement, and most important, no existing plan in place for the University and its Fraternity and Sorority Life Office to follow to enhance student learning and development (Norman, 2009). With the amount of change and growth in the Missouri S\&T campus over time, it is a likely understatement to say that this program review was long overdue.

Like many other recent campus Greek life program evaluations (e.g., Drexel, Purdue, Delaware, and Lehigh), this study was not conducted in order to be replicated and its findings are not be applicable to other campuses. Effective university administrators need to guide their Greek Life programs in a way that complements their institution's purpose through its application of program activities and dissemination of program information (Fulman \& Miles, 1992; Miller \& Winston, 1991). Therefore, a Greek Life program evaluation must supply accurate, quality findings that build the capacity of a program manager to think critically and to be able to interpret findings appropriately in order to use them to reach reasonable conclusions (Patton, 2002).

This study was conducted in order to gain some understanding about client perceptions of the Missouri S\&T Fraternity and Sorority Life Office. It was designed to gain a specific understanding of the desired expectations of some key constituents of the Missouri S\&T fraternities and sororities. Its desired outcome is to help enable those leading the Missouri S\&T Fraternity and Sorority Life Office to plan effectively to best 
meet its clients' needs and provide a new chapter in the history of Greek life at Missouri S\&T. 


\section{Appendix D}

\section{CAS Standards Stakeholders Assessment Questionnaire}

This survey is being conducted to collect information regarding the Missouri S\&T Fraternity and Sorority Life Office's programs from selected clients and stakeholders. The framework of this survey is based on the CAS Fraternity and Sorority Advisor Standards and the CAS Fraternity and Sorority Self-Assessment Guide. Elements of both of these documents have been adapted and incorporated into this document. The results of this survey's will be used to help set goals and formulate objectives for the Missouri S\&T Fraternity and Sorority Life Office. Please note that this evaluation is for program assessment and improvement purposes only and will not have any impact on personnel evaluations and performance reviews of staff in the Missouri S\& T Fraternity and Sorority Life Office.

Please read the following information and then provide your responses to this survey's questions.

The CAS Standards and Their Implications for the Missouri S\&T Fraternity and Sorority Life Office Fraternity and Sorority Life Offices should develop, disseminate, implement, and regularly review their programs and services. These activities must be consistent with the mission of their parent institution and with professional standards. Fraternity and Sorority Life Offices should also enhance overall educational experiences by incorporating student learning and development outcomes into their programs and services.

A. The Fraternity and Sorority Life Office's (FSLO) Implication for Chapters: To be consistent with the intent of these CAS standards, the Missouri S\&T Fraternity and Sorority Life Office should promote the academic and personal growth and development of students who affiliate with fraternities and sororities and should promote the fraternity and sorority community as an integral and productive part of the institution.

To fulfill these CAS Standards' expectations, the Missouri S\&T Fraternity and Sorority Life Office should:

- promote the intellectual, social, spiritual, moral, civic, and career development, and wellness of students.

- provide education and experience in leadership, group dynamics, and organization development.

- promote student involvement in co-curricular activities.

- promote sponsorship of and participation in community service and philanthropic projects.

- promote an appreciation for different lifestyles including cultural and religious heritages.

- recognize and encourage the positive learning experiences that are possible in a fraternity and sorority community that has a diversified membership.

B. The Fraternity and Sorority Life Office's (FSLO) Implications for Chapter Members: Participation in a campus chapter represents one of several group affiliation options for college students. Fraternity and sorority affiliation may include: a recruitment process, new/associate member education, initiation (formal induction into the organization), on-going membership development programming, and lifelong affiliation.

To fulfill these CAS Standards expectations, The Missouri S\&T Fraternity and Sorority Life Office should:

- develop a comprehensive program to promote the education and welfare of participating students.

- coordinate resources and activities with others in the campus community.

- promote responsible membership in both the organization and the institution.

\section{Missouri S\&T Mission Statement}

Missouri University of Science and Technology integrates education and research to create and convey knowledge to solve problems for our State and the technological world.

- We are a diverse scholarly community of hard-working problem-solvers who draw inspiration, strength, and pride from our history, our students' success, and our entrepreneurial spirit.

- We value the entire realm of human knowledge and seek to transcend boundaries in the pursuit of our goals.

- We encourage and depend upon mutual recognition and respect and the voluntary cooperative efforts of our diverse constituents to sustain a strong and cohesive scholarly community.

- We embrace academic integrity, exceptional results, and constant improvement in teaching, research, service, and economic development activities. 


\section{Please Respond to the Following Questions}

\section{Background Information}

1. Relationship with your Greek chapter (please check any that currently reflect your status with your chapter):
Chapter President:
Rush/Recruitment Chair:

Other Executive Officer:

If other is checked; identify Office Held:

2. Sex: Male: ___ Female:

3. Class year: First Year: ___ Sophomore: ___ Junior: __ _ _ Senior:

\section{Evaluation}

Please use the criterion below to evaluate the Missouri S\&T Fraternity and Sorority Life Office (FSLO) and provide your observations regarding this office's CURRENT LEVEL of compliance with following standards.
1- Very Poor/No Effort to Meet Criteria;
2-Poor/Criteria Not Met;
3 - Fair/Criteria Minimally Met;
4-good/Criteria Well Met;
5 - Very Good/Criteria Fully Met;
CE - Cannot Evaluate

1. The purpose of the Missouri S\&T Fraternity and Sorority Life Office is understood

by the Greek community members:

2. To comply with the CAS Standards described above, to what extent does the Fraternity and Sorority Life Office:

- conduct its activities in ways that are consistent with these standards

- incorporate learning and student development outcomes into its programs

- promote academic and personal growth and development of affiliated students

3. To what extent does the Fraternity and Sorority Life Office implement programs \& services that are consistent with Missouri S\&T's mission and values

4. To complement the Missouri S\&T Mission Statement, to what extent does the Fraternity and Sorority Life Office:

- promote the intellectual, social, spiritual, moral, civic \& career development, and wellness of students

- provide education \& experience in leadership, group dynamics, and organization development

- promote student involvement in co-curricular activities

- promote of sponsorship of and participation in community service and philanthropic projects

- promote of an appreciation for different lifestyles including cultural and religious heritages

- recognize and encourage the positive learning experiences that are possible in a fraternity and a sorority community that has a diversified membership

5. To what extent does the Fraternity and Sorority Life Office promote Greek communities as being integral to Missouri S\&T 
Appendix E

Date: $\quad$ April 5, 2013

To: $\quad$ Angela Perkins; Director of Student Life

C. C. All Student Life Department Staff Members

From: $\quad$ Debra Robinson; Vice Chancellor, Division of Student Affairs

Subject: Doctoral Research Project Involving the Fraternity and Sorority Life Office

As you may be aware, James Murphy, your immediate supervisor, is enrolled in the University of Missouri ELPA Doctoral Program. He has informed me that in the next few weeks he intends to conduct a study that will be a part the research for his dissertation. I am aware that his study will investigate Greek leaders' (student and alumni) perceptions of the Fraternity and Sorority Life Office's programs.

As Mr. Murphy's supervisor and as the senior officer of the Student Affairs Division, I am writing this memo to inform you that I am aware that this study will be taking place. I am also writing to assure you, the Student Life Department staff members and any survey participants that neither this study's findings or its data will be used in any way as a means to evaluate your performance, the performance of your department's staff or the programs associated with this department or the Fraternity and Sorority Life Office. Also understand that none of this study's findings or data will be incorporated into any decisions regarding pay adjustments or promotion opportunities for you or your department's staff.

I appreciate your attention to my note and encourage you, your staff or anyone who participates in this study to contact me if they have questions or concerns.

Thank you for your attention to my note. 


\section{Appendix F}

\section{Request to Participate in a Focus Group Discussion}

I am a doctoral student at the University of Missouri in Columbia who is studying stakeholder perceptions of programs and services provided to Greek chapters by the Missouri S\&T Fraternity \& Sorority Life Office. You are being asked to voluntarily participate in a focus group discussion. The information you provide is confidential. Your participation will provide a benefit by contributing to the understanding of stakeholder perceptions of programs and services provided to Greek chapters by the Missouri S\&T Fraternity \& Sorority Life Office. This project could potentially aid this office in determining how to improve the value of its programs for its stakeholders.

\section{NOTE: Your attendance at a focus group discussion indicates that you agree voluntarily to participate in this research effort.}

You Are Being Asked to Volunteer to Participate in a Study that is being done to help understand stakeholder perceptions of programs and services provided to Greek chapters by the Missouri S\&T Fraternity \& Sorority Life Office. You have the option of deciding whether you want to agree to participate. Your participation is voluntary, you may refuse to participate in this study and nothing will happen. Deciding to participate or not to participate will not have an effect on your relationship with Missouri S\&T.

What Risks Are Associated with being in this Study: There are no risks associated with participating in this study. Your identity will be protected and you will remain nameless in this study. If at, any time, you decide to stop participating in the study, you may do so.

Confidentiality: The information you provide is confidential. This Information will be kept in a secure location during any time it is not being used by the investigator. The data will also be kept confidential and viewed only by the investigator and members of a committee of professors at the University of Missouri.

If You Have Questions or Concerns: Please contact Dr. Jennifer Hart of the Department of Educational Policy Leadership and Analysis, College of Education, University of Missouri, Columbia, 202 Hill Hall, Columbia, Missouri 65211 , if you have questions about this study. You may also ask questions, voice concerns or complaints to the investigator.

Thank you for considering my request to complete this survey instrument. You providing your input on this topic is much appreciated. If there are words or phrases in this document that you do not understand, if you have any questions regarding this study or if I can be of any assistance please contact me.

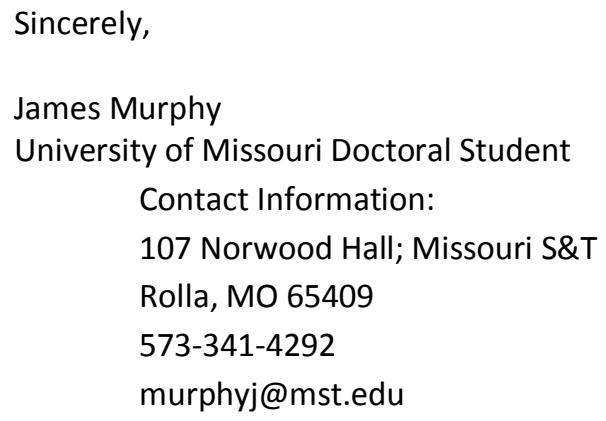




\section{Appendix G}

\section{Focus Groups \& Questions}

\section{CAS/Mission \& Program Stakeholders Focus Group Session Questions \& Guide}

Introduction: To be consistent with the CAS Standards for Fraternity and Sorority Advisors, the Missouri S\&T Fraternity and Sorority Life Office should:

- Promote academic and personal growth and development of students affiliated with fraternities and sororities.

- Promote a fraternity and sorority community that is an integral and productive part of Missouri S\&T.

This focus group session is being held to collect observations about how effectively these standards on the Missouri S\&T campus.

Introductory questions: To open the focus group session, group members are asked to introduce themselves and to acquaint themselves with each other by responding to couple of informal, preliminary questions. (Note: These questions are intended to initiate discussion by having group members respond with their experience in relation to agreeing to participate in this focus group.)

1. What has been the extent of each person's involvement in their Greek chapter?

2. What is each person's primary reason for participating in this discussion?

Transitional questions: The second phase of the discussion constitutes the primary purpose of the session. This portion of the discussion begins with one or two transition questions that help move participants' attention from why they chose to attend and toward the broad range of perspectives regarding the discussion topic. One or both of these questions are intended to get the group to start thinking about the topic at hand.

1. How have you observed the Fraternity \& Sorority Life Office promote academic and personal growth and the development of Greek students?

2. How have you observed the Fraternity \& Sorority Life Office promote growth and development of development the Greek chapters?

Primary discussion questions: These questions are intended to investigate how well the Missouri S\&T Fraternity and Sorority Life Office's programs align with the CAS Standards for Advising Fraternities and Sororities. (Note: The majority of the discussion is devoted to these questions). 
1. The Fraternity and Sorority Life Office should promote academic and personal development of Greek students. To define this purpose, what role should this Office play in;

- Encouraging students to become active members in Greek chapter and the University?

- Coordinating assistance provided to the Greek community from other campus sources?

- Developing a comprehensive plan for the education and welfare of Greek chapter members?

2. In order to accomplish its purpose, how can the Fraternity and Sorority life Office;

- Promote the intellectual, social, spiritual, moral, civic, and career development and wellness of Greek students?

- Provide educational experiences to that encourage leadership development, group dynamics, and organization development?

- Encourage Greek student involvement in co-curricular activities?

- Promote Chapter sponsorship of and member participation in community service and philanthropic projects?

- Promote an appreciation for different lifestyles, including cultural and religious heritages?

- Recognize and encouraging the positive learning experiences that are possible in a Greek chapter community that has a diversified membership?

Concluding questions: The last step is to draw the session to a close by asking members to summarize the discussion. Depending on the time available, and the length of responses one or more of the following questions will be used to help participants summarize common discussion themes.

1. What should be the mission of the Fraternity and Sorority Life Office?

- How does this mission differ from the current activities of this Office?

- What changes could be made in the Fraternity and Sorority Life Office that would effectively align it with its mission?

- What can this Office impact or promote student learning and development?

2. What should the Fraternity \& Sorority Life Office's primary objectives be providing program assistance to assistance to Greek students?

3. What should the Fraternity \& Sorority Life Office's primary objectives be in providing program assistance to chapter officers, active alumni \& advisors?

4. How should the Fraternity and Sorority Life Office attempt to collaborate with chapter officers, active alumni \& advisors? 


\section{Appendix $\mathrm{H}$}

\section{CAS Standards Survey Detail}

Responses: All (47); Presidents (12); Other Officers (35); Rush Chairs (2); Male (36); Female (11);

Response Scale: 1- Very Poor; No effort to meet criteria

3- Fair; Criteria minimally met

5- Very Good- Criteria fully met
2- Poor; Criteria not met

4- Good; Criteria well met

\section{Questions:}

1. The purpose of the Missouri S\&T Fraternity and Sorority Life Office is understood by the Greek community members:

Means: $\quad$ All - 3.77 Presidents - 3.92 Other Officers - 3.71 Male - 3.75 Female -3.82

\section{All/Presidents}

$P$ value and statistical significance:

The two-tailed $P$ value equals 0.5875

By conventional criteria, this difference is considered to be not statistically significant.

Confidence interval:

The mean of Group One minus Group Two equals 0.1500

95\% confidence interval of this difference: From -0.4005 to 0.7005

Intermediate values used in calculations:

$t=0.5456 \quad d f=57 \quad$ standard error of difference $=0.275$

\section{Other Officers/Presidents}

\section{$P$ value and statistical significance:}

The two-tailed $P$ value equals 0.4469

By conventional criteria, this difference is considered to be not statistically significant.

\section{Confidence interval:}

The mean of Group One minus Group Two equals - 0.2100

95\% confidence interval of this difference: From -0.7613 to 0.3413

Intermediate values used in calculations:

$t=0.7673 \quad d f=45 \quad$ standard error of difference $=0.274$

Female/Male

The two-tailed $P$ value equals 0.8064

By conventional criteria, this difference is considered to be not statistically significant.

\section{Confidence interval:}

The mean of Group One minus Group Two equals 0.0700

95\% confidence interval of this difference: From -0.5020 to 0.6420 
Intermediate values used in calculations:

$t=0.2465 \quad d f=45 \quad$ standard error of difference $=0.284$

2. To comply with the CAS Standards described above, to what extent does the Fraternity and Sorority Life Office:

a. Conduct its activities in ways that are consistent with these standards:

Means: $\quad$ All $-4.21 \quad$ Presidents -4.25 Other Officers - 4.20 Male $-4.22 \quad$ Female -4.18

All/Presidents

The two-tailed $P$ value equals 0.8737

By conventional criteria, this difference is considered to be not statistically significant.

Confidence interval:

The mean of Group One minus Group Two equals -0.0400

$95 \%$ confidence interval of this difference: From -0.5415 to 0.4615

Intermediate values used in calculations:

$t=0.1597 \quad d f=57 \quad$ standard error of difference $=0.250$

Other Officers/Presidents

The two-tailed $P$ value equals 0.8504

By conventional criteria, this difference is considered to be not statistically significant.

Confidence interval:

The mean of Group One minus Group Two equals 0.0500

$95 \%$ confidence interval of this difference: From -0.4810 to 0.5810

Intermediate values used in calculations:

$t=0.1897 \quad d f=45 \quad$ standard error of difference $=0.264$

Female/Male

The two-tailed $P$ value equals 0.8810

By conventional criteria, this difference is considered to be not statistically significant.

Confidence interval:

The mean of Group One minus Group Two equals - 0.0400

$95 \%$ confidence interval of this difference: From -0.5750 to 0.4950

Intermediate values used in calculations:

$t=0.1506 \quad d f=45 \quad$ standard error of difference $=0.266$

b. Incorporate learning and student development outcomes into its programs:

Means: $\quad$ All-4.00 Presidents-3.75 Other Officers - $4.09 \quad$ Male -3.94 Female -4.18

All/Presidents

The two-tailed $P$ value equals 0.3930

By conventional criteria, this difference is considered to be not statistically significant.

Confidence interval:

The mean of Group One minus Group Two equals -0.2500 
95\% confidence interval of this difference: From -0.8317 to 0.3317

Intermediate values used in calculations:

$t=0.8607 \quad d f=57 \quad$ standard error of difference $=0.290$

\section{Other Officers/Presidents}

The two-tailed $P$ value equals 0.0947

By conventional criteria, this difference is considered to be not quite statistically significant.

\section{Confidence interval:}

The mean of Group One minus Group Two equals 0.4500

95\% confidence interval of this difference: From -0.0810 to 0.9810

Intermediate values used in calculations:

$t=1.7070 \quad d f=45 \quad$ standard error of difference $=0.264$

Female/Male

The two-tailed $P$ value equals 0.8838

By conventional criteria, this difference is considered to be not statistically significant.

Confidence interval:

The mean of Group One minus Group Two equals 0.0400

95\% confidence interval of this difference: From -0.5082 to 0.5882

Intermediate values used in calculations:

$t=0.1470 \quad d f=45 \quad$ standard error of difference $=0.272$

c. Promote academic and personal growth and development of affiliated students:

Means: $\quad$ All - 4.24 Presidents -4.08 Other Officers - 4.29 Male $-4.17 \quad$ Female -4.45

\section{All/Presidents}

The two-tailed $P$ value equals 0.9747

By conventional criteria, this difference is considered to be not statistically significant.

\section{Confidence interval:}

The mean of Group One minus Group Two equals - 0.0100

95\% confidence interval of this difference: From -0.6414 to 0.6214

Intermediate values used in calculations:

$t=0.0319 \quad d f=45 \quad$ standard error of difference $=0.313$

Other Officers/ Presidents

The two-tailed $P$ value equals 0.4818

By conventional criteria, this difference is considered to be not statistically significant.

\section{Confidence interval:}

The mean of Group One minus Group Two equals - 0.2100

95\% confidence interval of this difference: From -0.8065 to 0.3865 
Intermediate values used in calculations:

$t=0.7095 \quad d f=44 \quad$ standard error of difference $=0.296$

Female/Male

The two-tailed $P$ value equals 0.9724

By conventional criteria, this difference is considered to be not statistically significant.

Confidence interval:

The mean of Group One minus Group Two equals 0.0100

95\% confidence interval of this difference: From -0.5688 to 0.5888

Intermediate values used in calculations:

$t=0.0348 \quad d f=44 \quad$ standard error of difference $=0.28$

3. To what extent does the Fraternity and Sorority Life Office implement programs \& services that are consistent with Missouri S\&T's mission and values:

Means: $\quad$ All $-4.30 \quad$ Presidents -4.50 Other Officers - 4.23 Male $-4.33 \quad$ Female -4.18

All/Presidents

The two-tailed $P$ value equals 0.4335

By conventional criteria, this difference is considered to be not statistically significant.

Confidence interval:

The mean of Group One minus Group Two equals 0.2000

95\% confidence interval of this difference: From -0.3077 to 0.7077

Intermediate values used in calculations:

$t=0.7888 \quad d f=57 \quad$ standard error of difference $=0.254$

Other Leaders/Presidents

The two-tailed $P$ value equals 0.3047

By conventional criteria, this difference is considered to be not statistically significant.

\section{Confidence interval:}

The mean of Group One minus Group Two equals -0.2700

95\% confidence interval of this difference: From -0.7938 to 0.2538

Intermediate values used in calculations:

$t=1.0382 \quad d f=45 \quad$ standard error of difference $=0.260$

Female/Male

The two-tailed $P$ value equals 0.5818

By conventional criteria, this difference is considered to be not statistically significant.

\section{Confidence interval:}

The mean of Group One minus Group Two equals - 0.1500

95\% confidence interval of this difference: From -0.6945 to 0.3945 
Intermediate values used in calculations:

$t=0.5548 \quad d f=45 \quad$ standard error of difference $=0.270$

4. To complement the Missouri S\&T Mission Statement, to what extent does the Fraternity and Sorority Life Office:

a. Promote the intellectual, social, spiritual, moral, civic \& career development, and wellness of students:

Means: All - 4.02 Presidents -4.17 Other Officers - 3.97 Male-3.97 Female -4.18

Other Officers/Presidents

The two-tailed $P$ value equals 0.4852

By conventional criteria, this difference is considered to be not statistically significant.

Confidence interval:

The mean of Group One minus Group Two equals 0.2000

$95 \%$ confidence interval of this difference: From -0.3724 to 0.7724

Intermediate values used in calculations:

$t=0.7037 \quad d f=45 \quad$ standard error of difference $=0.284$

All/Presidents

The two-tailed $P$ value equals 0.5668

By conventional criteria, this difference is considered to be not statistically significant.

Confidence interval:

The mean of Group One minus Group Two equals - 0.1500

$95 \%$ confidence interval of this difference: From -0.6714 to 0.3714

Intermediate values used in calculations:

$t=0.5761 \quad d f=57 \quad$ standard error of difference $=0.260$

Female/Male

The two-tailed $P$ value equals 0.4785

By conventional criteria, this difference is considered to be not statistically significant.

Confidence interval:

The mean of Group One minus Group Two equals 0.2100

95\% confidence interval of this difference: From -0.3818 to 0.8018

Intermediate values used in calculations:

$t=0.7148 \quad d f=45 \quad$ standard error of difference $=0.294$

b. Provide education \& experience in leadership, group dynamics, and organization development:

Means: $\quad$ All -4.13 Presidents -4.25 Other Officers $-4.09 \quad$ Male $-4.17 \quad$ Female -4.00

All/Presidents

The two-tailed $P$ value equals 0.6653

By conventional criteria, this difference is considered to be not statistically significant. 


\section{Confidence interval:}

The mean of Group One minus Group Two equals 0.1200

95\% confidence interval of this difference: From -0.4326 to 0.6726

Intermediate values used in calculations:

$t=0.4349 \quad d f=57 \quad$ standard error of difference $=0.276$

\section{Other Officers/Presidents}

The two-tailed $\mathrm{P}$ value equals 0.5999

By conventional criteria, this difference is considered to be not statistically significant.

Confidence interval:

The mean of Group One minus Group Two equals 0.1600

95\% confidence interval of this difference: From -0.4500 to 0.7700

Intermediate values used in calculations:

$t=0.5283 \quad d f=45 \quad$ standard error of difference $=0.303$

Female/Male

The two-tailed $P$ value equals 0.5883

By conventional criteria, this difference is considered to be not statistically significant.

Confidence interval:

The mean of Group One minus Group Two equals -0.1700

95\% confidence interval of this difference: From -0.7979 to 0.4579

Intermediate values used in calculations:

$t=0.5453 \quad d f=45 \quad$ standard error of difference $=0.312$

c. Promote student involvement in co -curricular activities:

Means: $\quad$ All $-4.11 \quad$ Presidents -4.33 Other Officers - 4.03 Male $-4.14 \quad$ Female -4.00

All/Presidents

The two-tailed $P$ value equals 0.4585

By conventional criteria, this difference is considered to be not statistically significant.

Confidence interval:

The mean of Group One minus Group Two equals 0.2200

95\% confidence interval of this difference: From -0.3702 to 0.8102

Intermediate values used in calculations:

$t=0.7464 \quad d f=57 \quad$ standard error of difference $=0.295$

Other Officers/Presidents

The two-tailed $P$ value equals 0.3467

By conventional criteria, this difference is considered to be not statistically significant.

Confidence interval:

The mean of Group One minus Group Two equals 0.3000 
95\% confidence interval of this difference: From -0.3354 to 0.9354

Intermediate values used in calculations:

$t=0.9510 \quad d f=45 \quad$ standard error of difference $=0.315$

Female/Male

The two-tailed $P$ value equals 0.6694

By conventional criteria, this difference is considered to be not statistically significant.

Confidence interval:

The mean of Group One minus Group Two equals - 0.1400

95\% confidence interval of this difference: From -0.7961 to 0.5161

Intermediate values used in calculations:

$t=0.4298 \quad d f=45 \quad$ standard error of difference $=0.326$

d. Promote sponsorship of and participation in community service and philanthropic projects:

Means: $\quad$ All -4.21 Presidents - 4.17 Other Officers - 4.23 Male -4.25 Female - 4.09

All/Presidents

The two-tailed $P$ value equals 0.8952

By conventional criteria, this difference is considered to be not statistically significant.

Confidence interval:

The mean of Group One minus Group Two equals - 0.0400

95\% confidence interval of this difference: From -0.6452 to 0.5652

Intermediate values used in calculations:

$t=0.1324 \quad d f=57 \quad$ standard error of difference $=0.302$

Other Officers/Presidents

The two-tailed $P$ value equals 0.8461

By conventional criteria, this difference is considered to be not statistically significant.

Confidence interval:

The mean of Group One minus Group Two equals - 0.0600

95\% confidence interval of this difference: From -0.6791 to 0.5591

Intermediate values used in calculations:

$t=0.1952 \quad d f=45 \quad$ standard error of difference $=0.307$

Female/Male

The two-tailed $P$ value equals 0.6149

By conventional criteria, this difference is considered to be not statistically significant.

Confidence interval:

The mean of Group One minus Group Two equals -0.1600

95\% confidence interval of this difference: From -0.7961 to 0.4761 
Intermediate values used in calculations:

$t=0.5066 \quad d f=45 \quad$ standard error of difference $=0.316$

e. Promote an appreciation for different lifestyles including cultural and religious heritages:

Means: $\quad$ All $-4.00 \quad$ Presidents -4.00 Other Officers - 4.00 $\quad$ Male $-3.94 \quad$ Female -4.18

All/Presidents

The two-tailed $\mathrm{P}$ value equals 1.0000

By conventional criteria, this difference is considered to be not statistically significant.

Confidence interval:

The mean of Group One minus Group Two equals 0.0000

95\% confidence interval of this difference: From -0.6205 to 0.6205

Intermediate values used in calculations:

$t=0.0000 \quad d f=57 \quad$ standard error of difference $=0.310$

Other Officers/Presidents

The two-tailed $P$ value equals 1.0000

By conventional criteria, this difference is considered to be not statistically significant.

Confidence interval:

The mean of Group One minus Group Two equals 0.0000

95\% confidence interval of this difference: From -0.6503 to 0.6503

Intermediate values used in calculations:

$t=0.0000 \quad d f=45 \quad$ standard error of difference $=0.323$

Female/Male

The two-tailed $\mathrm{P}$ value equals 0.4710

By conventional criteria, this difference is considered to be not statistically significant.

Confidence interval:

The mean of Group One minus Group Two equals 0.2400

95\% confidence interval of this difference: From -0.4250 to 0.9050

Intermediate values used in calculations:

$\mathrm{t}=0.7269 \quad \mathrm{df}=45 \quad$ standard error of difference $=0.330$

f. Recognize and encourage the positive learning experiences that are possible in a fraternity and a sorority community that has a diversified membership:

Means: $\quad$ All-4.09 Presidents - 3.75 Other Officers - 4.20 Male-4.03 Female -4.27

All/Presidents

The two-tailed $P$ value equals 0.2379

By conventional criteria, this difference is considered to be not statistically significant.

Confidence interval:

The mean of Group One minus Group Two equals -0.3400 
95\% confidence interval of this difference: From -0.9108 to 0.2308

Intermediate values used in calculations:

$t=1.1927 \quad d f=57 \quad$ standard error of difference $=0.285$

\section{Other Officers/Presidents}

The two-tailed $P$ value equals 0.1580

By conventional criteria, this difference is considered to be not statistically significant.

\section{Confidence interval:}

The mean of Group One minus Group Two equals - 0.4500

95\% confidence interval of this difference: From -1.0813 to 0.1813

Intermediate values used in calculations:

$t=1.4356 \quad d f=45 \quad$ standard error of difference $=0.313$

Female/Male

The two-tailed $P$ value equals 0.4712

By conventional criteria, this difference is considered to be not statistically significant.

Confidence interval:

The mean of Group One minus Group Two equals 0.2400

95\% confidence interval of this difference: From -0.4252 to 0.9052

Intermediate values used in calculations:

$t=0.7267 \quad d f=45 \quad$ standard error of difference $=0.330$

5. To what extent does the Fraternity and Sorority Life Office promote Greek communities as being integral to Missouri S\&T:

Means: $\quad$ All $-4.11 \quad$ Presidents -4.08 Other Officers - $4.12 \quad$ Male $-4.33 \quad$ Female -4.00

All/Presidents

The two-tailed $\mathrm{P}$ value equals 0.07021

By conventional criteria, this difference is considered to be not statistically significant.

The mean of Group One minus Group Two equals -0.0300

95\% confidence interval of this difference: From -0.6429 to 0.5829

Intermediate values used in calculations:

$t=0.0980 \quad d f=57 \quad$ standard error of difference $=0.306$

Other Officers/Presidents

The two-tailed $P$ value equals 0.7060

By conventional criteria, this difference is considered to be not statistically significant.

Confidence interval:

The mean of Group One minus Group Two equals - 0.1200

95\% confidence interval of this difference: From -0.7567 to 0.5167 
Intermediate values used in calculations:

$t=0.3796 \quad d f=45 \quad$ standard error of difference $=0.316$

Female/Male

The two-tailed $P$ value equals 0.6832

By conventional criteria, this difference is considered to be not statistically significant.

Confidence interval:

The mean of Group One minus Group Two equals - 0.1400

95\% confidence interval of this difference: From -0.8264 to 0.5464

Intermediate values used in calculations:

$t=0.4108 \quad d f=45 \quad$ standard error of difference $=0.341$ 


\section{Appendix I}

The CAS Standards 12 Common Criteria \& Specialty Standards for Fraternity and Sorority Advisors (reprinted from Mitstifer, 2012)

1. Mission: Programs and services must develop, disseminate, implement, and regularly review their missions. The mission must be consistent with the mission of the institution and with professional standards. The mission must be appropriate for the institution's student populations and community settings. Mission statements must reference student learning and development.

Fraternity and sorority advising specific standard; fraternity and sorority advising programs must:

- Promote the intellectual, social, spiritual, moral, civic, and career development, and wellness of students.

- Provide education and experience in leadership, group dynamics, and organization development.

- Promote student involvement in co-curricular activities.

- Promote sponsorship of and participation in community service and philanthropic projects.

- Promote an appreciation for different lifestyles including cultural and religious heritages.

- Recognize and encourage the positive learning experiences that are possible in a fraternity and sorority community that has a diversified membership.

2. Program: The formal education of students, consisting of the curriculum and the cocurriculum, must promote student learning and development outcomes that are purposeful, contribute to students' realization of their potential, and prepare students for satisfying and productive lives.

Fraternity and sorority advising specific standards: Fraternity and sorority advising programs must identify relevant and desirable student learning and development outcomes. When creating opportunities for student learning and development, fraternity and sorority advising programs must explore possibilities for collaboration with faculty members and other colleagues.

3. Leadership: Leaders with organizational authority for the programs and services must provide strategic planning, supervision, and management; advance the organization; and maintain integrity

Fraternity and sorority advising specific standards; because effective and ethical leadership is essential to the success of all organizations, fraternity and sorority advising program leaders must:

- articulate a vision and mission for their programs and services

- set goals and objectives based on the needs of the population served and desired student

- earning and development outcomes

- advocate for their programs and services

- promote campus environments that provide meaningful opportunities for student learning, development, and integration 
- identify and find means to address individual, organizational, or environmental conditions that foster or inhibit mission achievement

4. Human Resources: Fraternity and sorority advising programs must be staffed adequately by individuals qualified to accomplish mission and goals.

Fraternity and sorority advising specific standards - Within institutional guidelines, fraternity and sorority advising programs must:

- establish procedures for staff recruitment and selection, training, performance planning, and evaluation

- set expectations for supervision and performance

- assess the performance of employees individually and as a team

- provide access to continuing and advanced education and appropriate professional development opportunities to improve the leadership ability, competence, and skills of all employees

5. Ethics: Fraternity and sorority advising programs must review relevant professional ethical standards and must adopt or develop and implement appropriate statements of ethical practice.

Fraternity and sorority advising specific standards; fraternity and sorority advising programs must adopt a statement of ethics intended to:

- treat fairly prospective students who wish to affiliate with a fraternity/sorority

- eliminate illegal discrimination associated with the selection of members

- uphold applicable standards of conduct expressed by the institution and by the respective national or international organization

6. Legal Responsibilities: Fraternity and sorority advising programs must be in compliance with laws, regulations, and policies that relate to their respective responsibilities and that pose legal obligations, limitations, risks, and liabilities for the institution as a whole.

Fraternity and sorority advising specific standards; fraternity and sorority advising programs must:

- be in compliance with laws, regulations, and policies that relate to their respective responsibilities and that pose legal obligations, limitations, risks, and liabilities for the institution as a whole

- inform staff members, appropriate officials, and users of programs and services about existing and changing legal obligations, risks and liabilities, and limitations

- have written policies on all relevant operations, transactions, or tasks that have legal implications

- have procedures and guidelines consistent with institutional policy for responding to threats, emergencies, and crisis situations

7. Diversity, Equity and Access: Within the context of each institution's unique mission and in accordance with institutional polices and all applicable codes and laws, fraternity and sorority advising programs must create and maintain educational and work environments that are; welcoming, accessible, and inclusive to persons of diverse backgrounds; equitable and non-discriminatory, and; free from harassment. 
Fraternity and sorority advising specific standards; fraternity and sorority advising programs must:

- advocate for greater sensitivity to multicultural and social justice concerns by the institution and its personnel

- modify or remove policies, practices, facilities, structures, systems, and technologies that limit access, discriminate, or produce inequities

- include diversity, equity, and access initiatives within their strategic plans

- foster communication that deepens understanding of identity, culture, self-expression, and heritage

- promote respect about commonalities and differences among people within their historical and cultural contexts

- address the characteristics and needs of a diverse population when establishing and implementing culturally relevant and inclusive programs, services, policies, procedures, and practices

8. Institutional and External Relations: Fraternity and sorority advising programs must reach out to relevant individuals, groups, communities, and organizations internal and external to the institution to establish, maintain, and promote understanding and effective relations with those that have a significant interest in or potential effect on the students or other constituents served by the programs and services

Fraternity and sorority advising specific standards; fraternity and sorority advising programs must:

- garner support and resources for programs and services as defined by the mission statement disseminate information about the programs and services

- collaborate, where appropriate, to assist in offering or improving programs and services to meet the needs of students and other constituents and to achieve program and student outcomes

- engage diverse individuals, groups, communities, and organizations to enrich the educational environment and experiences of students and other constituents

9. Financial Resources: Fraternity and sorority advising programs must have funding to accomplish the mission and goals.

Fraternity and sorority advising specific standards: Fraternity and sorority advising programs must demonstrate efficient and effective use and responsible stewardship of fiscal resources consistent with institutional protocols.

10. Technology: Fraternity and sorority advising programs must have adequate technology to support the achievement of their mission and goals. The technology and its use must comply with institutional policies and procedures and be evaluated for compliance with relevant codes and laws.

Fraternity and sorority advising specific standards; fraternity and sorority advising programs must:

- maintain policies and procedures that address the security, confidentiality, and backup of data, as well as compliance with privacy laws

- have clearly articulated plans in place for protecting confidentiality and security of information when using Internet-based technologies

- develop plans for replacing and updating existing hardware and software as well as plans for integrating new technically-based or supported programs, including 
systems developed internally by the institution, systems available through professional associations, or private vendor-based systems

11. Facilities and Equipment: Fraternity and sorority advising programs must have adequate, accessible, and suitably located facilities and equipment to support the mission and goals. If acquiring capital equipment as defined by the institution, fraternity and sorority advising programs must take into account expenses related to regular maintenance and life cycle costs.

Fraternity and sorority advising specific standards: Staff members must have workspace that is well equipped, adequate in size, and designed to support their work and responsibilities. For conversations requiring privacy, staff members must have access to a private space.

12. Assessment and Evaluation - Fraternity and sorority advising programs must have a clearly articulated assessment plan to document achievement of stated goals and learning outcomes, demonstrate accountability, provide evidence of improvement, and describe resulting changes in programs and services.

Fraternity and sorority advising specific standards: Fraternity and sorority advising programs must have adequate fiscal, human, professional development, and technological resources to develop and implement assessment plans. Results of assessments and evaluations must be used to identify needs and interests in revising and improving programs and services, recognizing staff performance, maximizing resource efficiency and effectiveness, improving student achievement of learning and development outcomes, and improving student persistence and success. 
Appendix $\mathbf{J}$

Missouri S\&T Fraternity and Sorority Chapters

\section{Fraternity Chapter}

Kappa Alpha Order

Sigma Nu

Kappa Sigma

Pi Kappa Alpha

Lambda Chi Alpha

Triangle

Sigma Pi

Phi Kappa Theta

Sigma Tau Gamma

Alpha Epsilon Pi

Sigma Phi Epsilon

Tau Kappa Epsilon

Theta Xi

Beta Sigma Psi

Delta Sigma Phi

Alpha Phi Alpha

Delta Tau Delta

Pi Kappa Phi

Sigma Chi

Kappa Alpha Psi

Delta Lambda Phi

\section{Founding Date}

1903

1903

1905

1905

1917

1927

1933

1936

1956

1947

1947

1947

1949

1951

1956 - 1994 (suspended activities) /2008 (re-colonized)

1965

1966

1968

1983

2002

2009

\section{Notes}

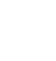

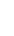

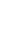




\section{Appendix K \\ Implications for Further Research}

Every study encounters limitations and challenges that provide opportunities for further research. In the following section, I identify areas that warrant further research.

More Consideration Given of the CAS Standards as Performance Standards

Consideration should be given to how the CAS Standards are used as a program evaluation performance standard. This study's findings indicate that, as used in this program evaluation, the CAS Standards were not as effective as had been reported in other studies. Most of the valuable insights gained through this study resulted from the focus group findings and not from the survey data.

The focus groups also afforded participants a limited opportunity to engage in interpretative discussions about the CAS Standards and their relevance to the Missouri S\&T Greek community. If the topic of the application of the CAS Standards had been explored more extensively, the resulting information may have provided insights as to how to improve applicability by modifying the survey and its accompanying instruction information materials.

An inquiry into the use of the CAS Standards may also suggest that because no comparisons will be made with other studies, a different, more conceptual, survey instrument that is designed for use only in this study may be a more effective at understanding the program under review.

Further inquiries might also yield other information about the relative value of focus groups in exploratory studies that utilize CAS Standards. While CAS Standards compliance is most often measured using survey instruments, this study suggests that focus groups can also provide valuable information not revealed by survey findings. 


\section{More Extensive Pre-Testing of Survey Information}

The CAS Standards survey that was distributed in this study was accompanied by information materials intended to instruct how to complete the survey questionnaire and educate any participants who were not familiar with the purpose and application of the CAS Standards. This educational material was similar to information distributed for like purposes at other university campuses. Two Missouri S\&T undergraduate students reviewed the material prior to distributing the survey for their ability to understand content.

I considered this to be a sufficient assurance that the instructions and survey information would be understood by the participating students. However, the focus group discussions indicated that some participants used a literal interpretation of the survey instructions. However, applying the CAS Standards in real settings requires interpreting how these standards correspond with the traits of the observed Greek community.

If I repeated this survey, I would arrange to better instruct the survey participants that the CAS Standards survey questions are to be interpreted as a performance measures within the context of the advising and service needs in the participants' Greek community. If a pre-test of this effort did not demonstrate a sufficient understanding of the purpose for using the CAS Standards, a different, more conceptual survey instrument would need to be designed and tested prior to proceeding with the study.

\section{A Longer Study}

Time constraints limited the amount of data collected. This study's focus groups were conducted near the end of the spring semester when new member recruitment is a predominant issue for many chapters. Through the academic year, there are re-occurring issues that are cyclical and can be anticipated on the academic calendar (e.g., pledge 
education in the fall semester, officer transitions between semesters, preparing national award bids through the spring semester). It is possible that the timing of data collection influenced the perspectives of the participants. If so, their perspective on the performance of the Fraternity and Sorority Life Office may also be different at various times in the academic year. A longer study with additional and more diverse focus groups held at different times during the academic year would potentially yield some different information. 


\section{REFERENCES}

Aburdene, P., \& Naisbett, J. (1992). Megatrends for Women. New York: Villard Books.

Asel, A. M., Seifert, T. A., \& Pascarella, E. T. (2009). Effects of Greek affiliation on college experiences and outcomes: A portrait of complexity. Oracle: The research journal of the association of fraternity advisors, 4(2), 1-15.

Association of Fraternity Advisors (2007). Core competencies for excellence in the profession. Retrieved September 9, 2009, from http://www.fraternityadvisors.org/Business/CoreCompetencies.aspx

Astin, A. W. (1992). What matters in college; four critical years revisited. San Francisco: Jossey-Bass.

Aston, J. L., \& Marchesani, R. F. (1991). Baird's manual of American college fraternities. (20th ed.). Indianapolis, IN: Baird's Manual Foundation.

Blimling, G. S. (1993). The influence of college residence halls on students. In J.S. Smart (Ed.), Higher education: Handbook of theory and research. New York: Agathon.

Bolman, L. G., \& Deal, T. E. (2003). Reframing organizations: artistry, choice and leadership. San Francisco: Jossey-Bass, V., \& Thompson, C. (1998, spring). The future of the Greek experience: Greeks and diversity. New Directions for Student Services, 81, 19-27.

Boyer, E. L. (1987). College: The undergraduate experience in America. New York: Harper \& Row.

Bresciani, M. J. (2006). Outcomes-based academic and co-curricular program review: A compilation of institutional good practices. Sterling, Va.: Stylus.

Brown, D. M. (2007). Transformational leadership behaviors and achieving styles of fraternity and sorority leaders. (Doctoral dissertation, Ohio University, 2007). 
Dissertation Abstracts International, 68, 05. (UMI No. 304831361). Retrieved August 8, 2009, from the Ohio Library and Information Network Web site: http://etd.ohiolink.edu/sendpdf.cgi/Brown\%20Danita\%20M.pdf?ohiou1178473599

Brown, J. T. (1920). Baird's Manual of American College Fraternities. (9th ed.). Indianapolis: Baird's Manual Foundation.

Brubacher, J. S., \& Willis, R. (1997). Higher education in transition: A history of American colleges and universities. New Brunswick, NJ: Transaction Publishers. Bryman, A. (2002). Triangulation. Unpublished manuscript. Retrieved Sept. 8, 2011, from Loughborough University: http://www.referenceworld.com/sage/socialscience/triangulation.pdf

Bullock, C., \& Ory, J. (2000). Evaluating instructional technology implementation in a higher education environment. America Journal of Evaluation, 21(3), 315-328.

Bureau, D. (2007, Winter). Barriers to greatness: Using the concept of relevancy to create urgency for change. Perspectives, 8-11.

Bureau, D. (2011). Using CAS Standards to Create Fraternity/Sorority Life Learning Outcomes. Paper presented at the Association of Fraternity/Sorority Advisors Annual Meeting, St. Louis, Mo.

Burns, J. M. (1978). Leadership. New York: Harper \& Row.

Carey, M. A., \& Smith, M. W. (1994). Capturing the group effect in focus groups: a special concern in analysis. Qualitative Health Research, 4(1), 123-127.

Callais, M. A. (2002). Sorority rituals: Rites of passage and their impact on contemporary sorority women. (Unpublished doctoral dissertation, Louisiana State University). Retrieved October 3, 2012, from the Louisiana State University 
Web site: http://etd.lsu.edu/docs/available/etd-0418102-

225829/unrestricted/Callais_dis.pdf

Chamberlin, M. K. (1991). Women in academe: Progress and prospects. New York, NY: Russell Sage.

Christensen, L. O., \& Ridley, J. B. (1983). UM-Rolla: A history of MSM/UMR.

Columbia, MO: University of Missouri Printing Services.

Cooper, D. L., \& Saunders, S. A. (2000). The perceived importance of the CAS standards: Implications for practice. College Student Affairs Journal, 19(2), 7181.

Cory, A. J. (2011). The influence of fraternity or sorority membership on the leadership identity development of college student leaders. (Unpublished doctoral dissertation, Washington State University). Retrieved October 3, 2012, from the Washington State University Web site:

http://research.wsulibs.wsu.edu/xmlui/bitstream/handle/2376/2920/Cory_wsu_02 51E_10175.pdf?sequence=1

Creswell, J. W. (2003). Research design: Qualitative, quantitative, and mixed methods approaches. Thousand Oaks, CA: Sage Publications.

Dean, L. A. (2006). CAS professional standards for higher education. (6th ed.). Washington, DC: Council for the Advancement of Standards in Higher Education.

Denzin, N. K., \& Lincoln, Y. S. (2000) Handbook of qualitative research. (2nd ed.). Thousand Oaks, CA, Sage Publications.

Dorman, J. A. (2012). Implementing the CAS Standards: The implementation of the CAS Standards in student affairs as a comprehensive assessment approach (Doctoral 
dissertation, George Washington University, 2012). Dissertation Abstracts International, 73, 08. (UMI No. 3503398).

Drout, C., \& Corsoro, C. (2003). Attitudes toward fraternity hazing among fraternity members, sorority members, and non-Greek students. Social Behavior and Personality: An International Journal, 31(6), 535-543.

Dugan, J. P. (2008). Exploring relationships between fraternity and sorority membership and socially responsible leadership. Oracle: The Research Journal of the Association of Fraternity Advisors, 3 (2), 16-25.

Eagly, A.H., \& Johannesen-Schmidt, M. C. (2001). The leadership styles of women and men. Journal of Social Issues, 57(4), 781-797.

Eberhart, D., Rice, N. D., \& Smith, L. D. (2003). Effects of Greek membership on academic integrity, alcohol abuse, and risky sexual behavior at a small college. The NASPA Journal: The Journal of Student Affairs Administration, 41(1), 137148.

Field, A. P. (2005). Discovering statistics using SPSS. London: Sage Publications.

Fraenkel, J. R., \& Wallen, N. E. (2003). How to design and evaluate research in education (5th ed.). Boston: McGraw Hill.

Gregory, D. E. (2003). The dilemma facing fraternal organizations at the Millennium. In D. E. Gregory \& Associates (Eds.), The administration of fraternal organizations on North American campuses: A pattern for a new millennium (pp. 3-23).

Asheville, N.C.: College Administration Publications.

Hammersley, M. (2008). Troubles with triangulation. In B. M. Max (Ed.), Advances in Mixed Methods Research (pp. 22-36). London: Sage Publications. 
Heppner, P. P., \& Heppner, M. J. (2004). Writing and publishing your thesis, dissertation \& research: A guide for students in the helping professions. Belmont, CA: Brooks/Cole-Thomson.

Hogan, R. L. (2007). The historical development of program evaluation: exploring the past and present. Online journal of workforce development and program evaluation. 2(4), 2-14. Retrieved March, 2012, from http://wed.siu.edu/Journal/VolIInum4/Article_4.pdf.

Hollander, E. P., \& Offermann, L. R. (1990). Power and leadership in organizations: Relationship in transition. The American Psychologist. 45(2), 179-189.

Hunt S., \& Rentz A. (1994). Greek-letter social group members' involvement and psychosocial development. Journal of College Student Development, 35(4), 289295.

Jelke, T. B. (2001). A cross-case analysis of Greek systems perceived to be high performing. (Doctoral dissertation, Indiana University, 2001). Dissertation Abstracts International 62, 08. (UMI No. 3503398).

Jelke, T. B., \& Kuh, G. D. (2003). High performing fraternities and sororities. In D. E. Gregory (Ed.), The administration of fraternal organizations on North American campuses: A pattern for the new millennium (pp. 275-298). Asheville, NC: College Administration Publications.

Jick, T. D. (1979). Qualitative Methodology. Administrative Science Quarterly, 24(4), 602-611. Retrieved September 8, 2011, from http://links.jstor.org/sici?sici=00018392\%218 9791 2\%2924\%3A4\%3C602\%3AMQAQMT\%3E2.O.C0\%3B2-Q

Johnson, C. S. (1972). Fraternities in our colleges. New York, NY: National Interfraternity Foundation. 
Kalkowski, K. L. (2005). Exploring leader-member exchange and organizational citizenship behavior in a college setting: The influence of the fraternity housemother (Doctoral dissertation, University of Nebraska, Lincoln, 2005). Dissertation Abstracts International, 66, 08. (UMI No. 3186860).

Kelly, D. R. (2008). Leadership development through the fraternity experience and the relationship to career success after graduation. Oracle: The Research Journal of the Association of Fraternity Advisors, 3(1), 1-12.

Keeling, P. P. (2006). Learning Reconsidered 2: Implementing a Campus wide Focus on the Student Experience. Washington: ACPA

Kennerley, M., \& Neely, A. D. (2002) Performance measurement frameworks chapter. In A. D. Neely (Ed.), Business Performance Measurement: Theory and Practice (pp. 145-152). Cambridge University Press, New York. Retrieved January 15, 2011, from http://books.google.com/books?hl=en\&lr=\&id=1 KIEoQYx5ewC\&oi=fnd\&pg=P A145\&dq=stakeholder+satisfaction \&ots $=\mathrm{fBcXVkP2up \& sig=TgGDf7HdHsy3abi}$ SaOeNg0h0FSk\#v=onepage $\& \mathrm{q}=$ stakeholder satisfaction $\& \mathrm{f}=\mathrm{fals}$

Koepsell, M. (2008). Utilizing community standards to align accountability, assessment and performance. Retrieved September 9, 2009, from http://www.fraternityadvisors.org/Essentials/20085_Community_Standards.aspx

Kohen, L. T. (1997)Methods in case study analysis. The center for studying health systems change, technical publication \# 2. Retrieved October 17, 2012 from http://webanketa.com/direct/upload/books/en/methods_in_case_study_analysis_b y_linda_t_kohn.pdf\#page $=1 \& z$ zoom $=$ auto, 0,800 
Komives, S. R., \& Woodard, D. Jr. (Eds.). (2003). Student services: A handbookfor the profession (4th ed.). San Francisco: Jossey-Bass.

Krueger, R. A. (1994). Focus groups: A practical guide for applied research. Thousand Oaks, CA: Sage Publications.

Krueger, R. A., \& Casey, M. A. (2000). Focus groups: A practical guide for applied research.

(3rd ed.). Thousand Oaks, CA: Sage Publications.

Kuh, G. D. (1991). Characteristics of involving colleges. In G. D. Kuh \& J. H. Schuh (Eds.), The role and contribution of student affairs in involving colleges (pp. 1129). Washington, DC: National Association of Student Personnel Administrators.

Kuh, G. D., \& Gonyea, R. M. (2006). Spirituality, liberal learning, and college student engagement. Liberal Education 92(5), 40-47.

Lindlof, T. R., \& Taylor, B. C. (2002). Qualitative Communication Research Methods. (2nd ed.). Thousand Oaks, CA: Sage Publications.

Lloyd, M. (2005). A history of alpha kappa chapter of pi kappa alpha fraternity, Rolla, Mo 1905 - 2005. Topeka, KS: Jostens publications.

Mable, P. (1991). Professional standards: An introduction and historical perspective. In W. A. Bryan, R. B. Winston, Jr., \& T. K. Miller (Eds.), Using professional standards in student affairs: New directions for student services. (pp. 5-18). San Francisco: Jossey-Bass.

Maisel, J. M. (1990). Social fraternities and sororities are conducive to the educational process. NASPA Journal: The Journal of Student Affairs Administration, 28(1), 812. 
Mamarchev, H. L., Sina, J. A., \& Heida, D. E. (2003). Creating a comprehensive worldview approach for managing a campus oversight plan: Do they work? What are the alternatives? In D. E. Gregory \& Associates (Eds.). The administration of fraternal organizations on North American campuses: A pattern for a new millennium (pp. 347- 355). Asheville, N.C.: College Administration Publications. McCabe, D. L., \& Bowers, W. J. (1996). The relationship between student cheating and college fraternity and sorority membership. NASPA Journal: The Journal of Student Affairs Administration, 33(4), 280-291.

McQuarrie, E. F. (2006). The market research toolbox: A concise guide for beginners. (2nd ed.). Thousand Oaks, CA: Sage Publications.

Merriam, S. B. (1998). Qualitative research and case study applications in education. San Francisco: Jossey -Bass.

Miller, T. K. (2003). The CAS book of professional standards for higher education. (5th ed.). Washington: Council for the Advancement of Standards in Higher Education.

Missouri S \& T, Office of the Chancellor. Strategic plan: fy2010 - fy2014. (2010, October). Retrieved November 7, 2011, from http://chancellor.mst.edu/documents/planning/FY11-15_Strategic_Plan.pdf

Missouri S \& T, Office of Institutional Research and Assessment. 2009-2010 Common data set. (2010). Retrieved January 3, 2010, from http://ira.mst.edu/documents/cds/cds_MST_2009-10.xls

Missouri S \& T, Department of Student Life. Student organization policies. (2011, December). Retrieved January 3, 2012, from http://studentlife.mst.edu/organizations/policies/polpro/index.html 
Missouri S \& T, Office of Fraternity and Sorority Life. Overview. (2011, May). Retrieved January 3, 2012, from http://studentlife.mst.edu/greek/

Missouri S \& T, Office of the Vice Chancellor for Student Affairs. Community Standards. (2011, December). Retrieved January 3, 2012, from http://communitystandards.mst.edu

Mitstifer, D. I. (2012). CAS professional standards for higher education. (8th ed.). Washington, DC: Council for the Advancement of Standards in Higher Education. Morgan, D. L. (1993). Successful focus groups advancing the state of the art. Thousand Oaks, CA: Sage Publications.

Morgan, G. (1997). Images of an organization. Thousand Oaks, CA: Sage Publications. Neuman, W. L. (1997). Social research methods: qualitative and quantitative approaches. (3rd ed.). Boston: Allyn and Bacon.

Norman, E. (2009, August). Consultant summary of community standards best practice recommendations for Missouri S\&T. Unpublished manuscript.

Owen, K. C. (1991). Reflections on the college fraternity and its changing nature. In J. L. Anson \& R.F. Marchesani, Jr. (Eds.), Baird's manual of American college fraternities. (20th ed.). (pp. I1 - I24). Indianapolis, IN: Baird's Manual Foundation.

Pascarella E. T,. \& Terenzini, P. T. (2005). How college affects students: A third decade of research (Rev. ed.). San Francisco: Jossey-Bass.

Paterson, B. G., \& Carpenter, D. S. (1989). The emerging student affairs profession: What still needs to be done. NASPA Journal: The Journal of Student Affairs Administration, 27(2), 123-127. 
Patton, M. Q. (1990). Qualitative Evaluation and Research Methods. (2nd ed.). Newbury Park: CA: Sage Publications.

Patton, M. Q. (1997) Utilization-focused Evaluation. (3rd ed.). Newbury Park, CA: Sage Publications.

Patton, M. Q. (2002). Qualitative research and evaluation methods. Thousand Oaks, CA: Sage Publications.

Preskill, H., \& Torres, R. (1999). Evaluative inquiry for learning in organizations. Thousand Oaks, CA: Sage Publications.

Roberts, C. N. (1946). History of the University of Missouri School of Mines and Metallurgy. Retrieved March 3, 2011, from http://archive.org/details/historyoftheuniv009393mbp

Sandeen, A., \& Barr, M. J. (2006). Critical issues for student affairs: Challenges and opportunities. San Francisco: Jossey-Bass.

Scroggs, C. C. (1994). Transformational leadership characteristics and achieving styles of selected student leaders. (Doctoral dissertation, University of Missouri, Columbia, 1994). Dissertation Abstracts International, 55, 12.

Seidman, I. (2006). Interviewing as qualitative research: A guide for researchers in education and the social sciences, (3rd ed.). New York: Teachers College Press.

Shepard, L. A. (2005, October 10-11). Formative assessment: Caveat emptor. Paper presented at the Educational Testing Service invitational conference: The future of teaching and learning, New York. Retrieved August 1, 2012, from http://www.cpre.org/ccii/images/stories/ccii_pdfs/shepard\%20formative\%20asses sment $\% 20$ caveat $\% 20$ emptor.pdf 
Shields, P., \& Hassan T. (2006). Intermediate theory: The missing link in successful student scholarship. Journal of Public Affairs Education 12(3), 313-334. Retrieved May 17, 2012, from http://ecommons.txstate.edu/polsfacp/39/

Stake, R. E. (1995). The art of case study research. Thousand Oaks, CA: Sage Publications. Retrieved September 10, 2011, from http://books.google.com/books?hl=en\&lr=\&id=ApGdBx76b9kC\&oi=fnd\&pg=PR $11 \& d q=$ stake $+1995+$ case + study+research\&ots=KtLM16Ikcq\&sig=cDWbYmqBB UNNAcpHSwlv0u0blw0\#v=onepage \&q=stake\%201995\%20case \%20study\%20re search $\& \mathrm{f}=$ false

Stayhorn, T. L. (2006). Frameworks for assessing learning and development outcomes. Hagerstown, MD: HBP.

Stewart, D. W., Shamdasani, P. N., \& Rook, D. W. (2007). Focus groups; Theory and practice. (2nd ed.). Thousand Oaks, CA: Sage Publications.

Teamworks Inc. Continuous improvement. (2011). Retrieved August 8, 2012, from http://www.teamworks2002.com/continuous-improvement/

Thurmond, V. A. (2001). The point of triangulation. Journal of Nursing Scholarship, 33(3), 253-259. Retrieved January 15, 2013, from http://www.utas.edu.au/_data/assets/pdf_file/0004/165208/the-point-oftriangulation.pdf

Tinto, V. (1993). Leaving college; rethinking the causes and cures of student attrition. Chicago: University of Chicago Press.

Trochim, W. M. K. (2006). Research Methods Knowledge Base. Retrieved June 2, 2010, from http://www.socialresearchmethods.net/ kb/sampnon.htm 
Turk, D. B. (2004). Bound By a mighty vow: sisterhood and women's fraternities; 18701920. New York: NYU Press.

Tyler, R. W. (1980). A brief overview of program evaluation. Journal of Cooperative Education and Internships, 16, 62-68.

Umbach, P. D. (2004). Web surveys: best practices. New Directions for Institutional Research. (121)(spring), 23-38. Retrieved March 16, 2013, from http://www.uwyo.edu/studentaff/_files/docs/survey_calendar/umbach_web_surve ys_best_practices.pdf

Upcraft, M. L., \& Schuh, J. H. (1996). Assessment in student affairs: A guide for practitioners. San Francisco: Jossey-Bass.

Viles, J. (1939). The University of Missouri, a centennial history. Columbia, Mo: University of Missouri Press.

Webb, E. J., Campbell, D. T., Schwartz, R. D., \& Sechrest, L. (1966). Unobtrusive measures: nonreactive measures in the social sciences. Chicago: Rand McNally.

Whipple, E. G., \& Sullivan, E. G. (1998). Greek-letter organizations: A community of learners? In E. G. Whipple (Ed.). New challenges for Greek-letter organizations: Transforming fraternities and sororities into learning communities. San Francisco, CA: Jossey-Bass.

White, E. R. (2006).Using CAS Standards for Self-Assessment and Improvement. Retrieved Sept. 8, 2011, from http://www.nacada.ksu.edu/Clearinghouse/AdvisingIssues/CAS.htm Yin, R. (1993). Applications of case study research. Beverly Hills, CA: Sage Publishing. Yin, R. (1994). Case study research: Design and methods (2 ${ }^{\text {nd }}$ ed.). Beverly Hills, CA: Sage Publishing. 
Yukl, G. (2002). Leadership in organizations. Upper Saddle River, NJ: Prentice Hall. 
VITA

James (Jim) Murphy was born in Oshkosh, Wisconsin June 12, 1958. He graduated from Valders High School in 1976. He received his Bachelor of Science in Social Studies in 1980 from the University of Wisconsin - Stevens Point, Master of Education in Student Development 1984 from the University of Wisconsin - Stout, and Doctor of Education in Educational Leadership and Policy Analysis (to be conferred in December 2013) from the University of Missouri.

James Murphy began his professional career in 1981 with the Residential Life Department at the University of Wisconsin - Stout as a Resident Director. In 1984, he next accepted a Program Coordinator position in the Creighton University Student Affairs Division where he worked primarily coordinating the University's residential programs. Since 1988 James has worked for Missouri S\&T (formerly the University of Missouri - Rolla) first as its Director of Residential Life, then as Director of its Auxiliary Services. Since 2003, Jim has been the Missouri S\&T Student Affairs Division's Assistant Vice Chancellor.

Jim has had a long standing involvement in various professional associations including the National Association of Student personnel Administrators (NASPA), the Association of College Personnel Administrators (ACPA), the National Association of College \& University Business Officers (NACUBO), and the Association of College \& University Housing Officers - International (ACUHO-I).

Jim lives with his wife Phyllis live in Rolla, Missouri. They have three adult children (Erin, Marn, and Patrick), two sons-in-law (Adam and Nick), and two granddaughters (Amelia and Caroline). 